Research Article

\title{
Numerical Simulation Research of Smooth Wall Blasting Using the Timing Sequence Control Method under Different Primary Blast Hole Shapes
}

\author{
XinPing Li, ${ }^{1}$ JunLin Lv $\mathbb{D}^{1,2},{ }^{1,2}$ JunHong Huang $\mathbb{D}^{3,4}$ Yi Luo $\mathbb{D}^{1},{ }^{1}$ and TingTing Liu $\mathbb{C}^{1}$ \\ ${ }^{1}$ Hubei Key Laboratory of Road-bridge and Structure Engineering, Wuhan University of Technology, Wuhan 430070, China \\ ${ }^{2}$ School of Civil Engineering and Architecture, Wuhan University of Technology, Wuhan 430070, China \\ ${ }^{3}$ School of Resource, Environmental Science and Engineering, Hubei University of Science and Technology, \\ Xianning 437100, China \\ ${ }^{4}$ School of Safety Science and Emergency Management, Wuhan University of Technology, Wuhan 430070, China \\ Correspondence should be addressed to JunHong Huang; junhonghuang@whut.edu.cn
}

Received 15 November 2018; Revised 3 March 2019; Accepted 1 April 2019; Published 9 May 2019

Academic Editor: Salvatore Russo

Copyright (c) 2019 XinPing Li et al. This is an open access article distributed under the Creative Commons Attribution License, which permits unrestricted use, distribution, and reproduction in any medium, provided the original work is properly cited.

\begin{abstract}
To make sure the integrity and stability of surrounding rock structure during blasting excavation of important structural planes in deep underground caverns, two kinds of fine blasting methods, timing sequence control fracture blasting network and notch blast hole, are innovatively combined and the formation of cracks between smooth blasting holes with different delay initiation and different shapes of primary blast holes (PBHs) are compared and analyzed. The results show that when the delay initiation time between the successive explosion holes is greater than or equal to the transverse wave of the $\mathrm{PBH}$ propagates to the target blast hole (TBH), the concentrated stress along the connection direction of the hole on the wall of the TBH is larger than the other directions of the hole wall. After the TBH is detonated, cracks will preferentially expand along the connection direction of the blast holes. If the $\mathrm{PBH}$ is the notch blast hole, more explosive energy will be directed to the wall of the TBH so that the hole wall along the connection direction of the blast holes will be subjected to greater tension stress before the initiation of the TBH. In this way, the interval between successive holes can be increased and the efficiency of blasting excavation of rock mass can be improved accordingly.
\end{abstract}

\section{Introduction}

At present, the hydropower projects under construction in southwest and northwest China are mostly in the mountains, they generally adopt the structures of underground caverns in the process of engineering construction, and underground cavern excavation still mainly uses the blasting method. Although blasting excavation is economic and efficient, the instantaneous explosion and detonation will produce strong shock and vibration, so the disturbance and damage to nearby rock mass caused by explosion excavation must be considered. Cai et al. $[1,2]$ have summarized the threshold value of brittle rock crack initiation and crack expansion in the underground cavern excavation through the analysis of a large number of surrounding rock characteristics formed after excavation. Ma and An [3] and
Zhu et al. [4] studied the damage and crack propagation process of rock under explosion loading by the method of numerical simulation.

In the process of underground cavern excavation, though the smooth blasting method can be used on the contour line, the explosion loading can still produce different levels of damage to the nearby rock mass. In the process of the follow-up blasting excavation, the explosive stress wave will produce further damage to the surrounding rock of already excavated section of cavern and induce further extension of the initial damage zone [5]. Therefore, in smooth blasting excavation, not only the amount of explosive should be controlled but also the damage to the surrounding rock should be reduced. Some advanced technology should be used to apply more explosive energy to the crack formation between the blast holes. 
Traditional smooth blasting usually adopts the structure of uncoupled charge or air interval charging, and this method has a certain protective effect on the surrounding rock, but it is difficult to achieve quality requirements for the structures which require high precision such as underground powerhouse rock anchor beam. Some researchers have tried to get it by reducing the blast hole spacing and reducing charging, but this often tends to reduce the work efficiency significantly.

In order to guarantee that the contour line of smooth blasting is smooth and reduce the dynamic damage of the retained rock mass, this paper puts forward TSC method for blasting excavation. The TSC blasting is achieved by controlling the initiation time and sequence between primary blast holes (PBHs) and target blast holes (TBHs), and the $\mathrm{TBH}$ will be detonated after the blast hole wall of $\mathrm{TBH}$ has produced concentrated stress so that the superimposition effect of stress waves between blast holes increases and concentrates more explosion energy for the crack formation.

Rossmanith and Kouzniak [6] have described a 2D model which reveals how a positive effect of shock wave interaction can be achieved. Blair [7] argues that stress waves in the field are never similar in shape and even if there are shock wave interactions, they are quite localized, i.e., a small fraction of the total volume will be influenced. Khandelwal and Singh [8] demonstrated the advantage of the accurate time-delay controlled blasting technology in reducing vibration and improving rock fracture effect by experiments successfully. The influence of time delays on fragmentation has been investigated through small-scale experiments, field trials, and numerical simulations $[9,10]$.

However, TSC blasting can through the explosive stress wave of $\mathrm{PBH}$ produce the concentration stress effect in the blast hole wall of $\mathrm{TBH}$. However, random radial cracks inevitably occur in the blast hole wall of $\mathrm{PBH}$, and the damage to surrounding rock can be reduced by directional blasting through the notched technology. Longerfors and Kihstrom [10] proposed that the formation of cracks in other directions and the formation of fracture planes can be controlled by pregrooving along the direction of the blast holes connection in the hole wall. The V-shaped notch hole has prefabricated initial crack on the inner wall of the blast hole, and the prefabricated initial cracks will play the role of stress concentration and energy guidance, which will make the rock fracture preferentially along the direction of notch under the action of explosive load and also play a protective role to the reserved rock mass [11].

Fourney et al. [12] put forward the method using the axial lancing cartridge in blast holes to form oriented cracks in rock mass. They conducted a series of experiments of controlled blasting with clearance casing charge, which proved that controlled fracture can be obtained during blasting. Liang et al. [13] found there would be obvious dynamic stress concentration at notch tips from notching blasting experiments on metal cylinders. As the V-shaped notch blast hole technology is complex, only notch the $\mathrm{PBH}$, and do comparative analysis with the round hole $\mathrm{TBH}$ and round hole $\mathrm{PBH}$ successively, to find the most suitable for the actual excavation method. Because of the complexity of V-shaped notch blast hole technology, only the $\mathrm{PBH}$ is notched, and comparing with the case that the $\mathrm{PBH}$ and $\mathrm{TBH}$ are round holes, the most suitable excavation method is found out.

In conclusion, both TSC blasting and notch blasting methods can reduce the damage effect on surrounding rock to a certain extent and improve the smoothness of cracks between blast holes. In this paper, the formation of cracks between smooth blasting holes with different delay initiation and different shapes of $\mathrm{PBH}$ is studied in combination with the methods of TSC blasting and notch blast hole. The delay law between successive blast holes and the approximate relationship between the hole spacing and the hole diameter under different shapes of the $\mathrm{PBH}$ are obtained.

\section{Stress Concentration Effect on Blast Hole Wall of TBH}

When the stress wave of $\mathrm{PBH}$ reaches the $\mathrm{TBH}$, TBH with radial uncoupled charge is like an empty hole, the hole wall of TBH will produce larger stress concentration effect. In order to fully consider the effect of rock mass material properties on wave velocity, the longitudinal wave velocity $C_{\mathrm{P}}$ and the transverse wave velocity $C_{\mathrm{S}}$ in the rock mass can be calculated from the following equation Yang [14]:

$$
\begin{aligned}
& C_{\mathrm{P}}=\sqrt{\frac{E(1-\nu)}{(1+\nu)(1-2 \nu) \rho}}, \\
& C_{\mathrm{S}}=\sqrt{\frac{G}{\rho}},
\end{aligned}
$$

where $E$ represents the modulus of elasticity of rock mass, $v$ represents Poisson's ratio of rock mass, and $\rho$ represents the rock density.

Blair [15] proposed the following equation to account for the pressure history in the blast hole and to ensure that the pressure on the rock mass unit changes dynamically with time:

$$
P(t)=P_{\mathrm{VN}}\left(\frac{e \gamma}{n}\right)^{n} H(t) t^{n} e^{-\gamma t}
$$

where $P_{\mathrm{VN}}$ is the (von Neumann) explosive pressure generated by the detonation of the explosive in the blast hole, $H(t)$ is the Heaviside unit step function, $n$ is an integer, and $\gamma$ is the pressure decay parameter.

In practical engineering, the size of the hole relative to the rock is very small, so the rock mass stress wave of the hole can be approximated as a plane wave. The longitudinal wave is faster than the transverse wave, so the longitudinal wave of the $\mathrm{PBH}$ will first reach the $\mathrm{TBH}$, produce radial tensile force, and set the size of the stress $q_{1}$. When the transverse wave reaches the blast hole, the tangential tensile stress on the wall of the hole is denoted as $q_{2}$. When the TBH is only reached by longitudinal waves of $\mathrm{PBH}$, the stress diagram on the hole wall is shown in Figure 1.

Under the condition of static force, according to the derivation of Yang [14] and Jaeger et al. [16], the stress component of the surrounding rock mass is given by 


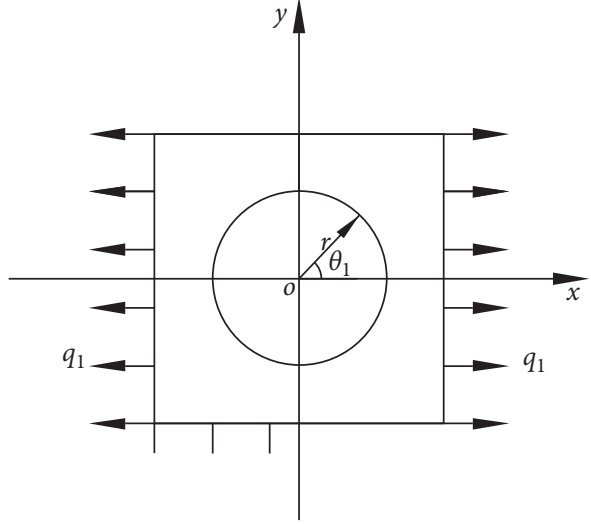

(a)

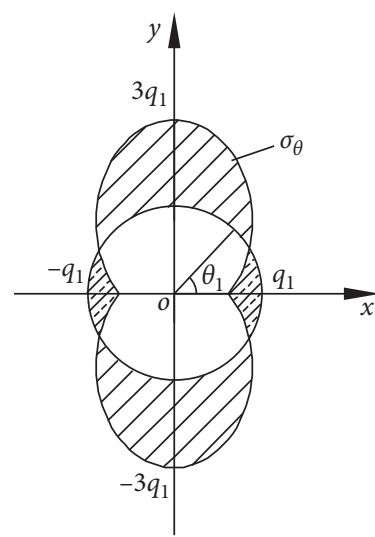

(b)

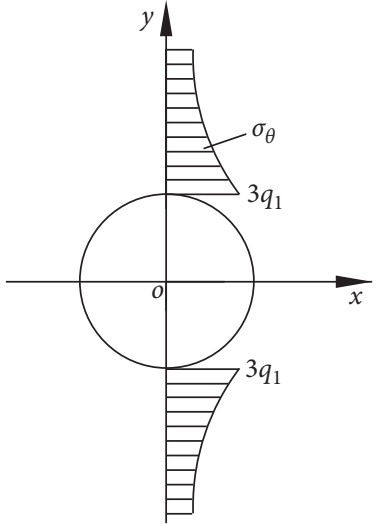

(c)

FIgURE 1: The diagram of stress concentration on the hole wall of the empty hole due to the longitudinal wave. (a) Empty hole subjected to uniformly distributed horizontal forces. (b) Hole wall stress. (c) Hole edge stress.

$$
\left.\begin{array}{l}
\sigma_{r}=\frac{1}{2} q\left[1-\frac{a^{2}}{r^{2}}+\left(1-\frac{4 a^{2}}{r^{2}}+\frac{3 a^{4}}{r^{4}}\right) \cos 2 \theta\right] \\
\sigma_{\theta}=\frac{1}{2} q\left[1+\frac{a^{2}}{r^{2}}-\left(1+\frac{3 a^{4}}{r^{4}}\right) \cos 2 \theta\right] \\
\tau_{r \theta}=-\frac{1}{2} q\left(1+\frac{2 a^{2}}{r^{2}}-\frac{3 a^{4}}{r^{4}}\right) \sin 2 \theta
\end{array}\right\} .
$$

For the hole, scholars are concerned about the stress in the hole wall. When $r=a$, then $\sigma_{r}=0, \tau_{r \theta}=0$, and $\sigma_{\theta}=$ $q(1-2 \cos 2 \theta)$. As shown in Figure $1, r=a, \theta= \pm \pi / 2$, and then $\sigma_{\theta}=3 q$. The maximum tensile stress of the hole is three times of the average tensile stress. When $\theta=0$ or $\theta=\pi$, then $\sigma_{\theta}=-q$, and the edge of the hole is subjected to compressive stress.

When $\theta= \pm \pi / 2$, the relationship between $\sigma_{\theta}$ and $r$ is given by

$$
\sigma_{\theta}=q\left(1+\frac{a^{2}}{2 r^{2}}+\frac{3 a^{4}}{2 r^{4}}\right) .
$$

From the above equation, when $r=2 a, \sigma_{\theta}=1.22 q$, and $r=3 a$, then $\sigma_{\theta}=1.07 q$. When $r$ is big enough, $\sigma_{\theta} \longrightarrow q$, so the effect of stress concentration occurs only in the near empty hole, and it is rapidly attenuated away from the wall of the hole. Similarly, when the TBH is only affected by the transverse wave of the $\mathrm{PBH}$, along the hole line direction (that is, $\theta=0$ or $\theta=\pi$ ), the maximum tensile stress on the hole wall is $3 q$. When $\theta= \pm \pi / 2$, then the maximum stress of the hole wall is $q$.

Similarly, after the stress wave of $\mathrm{PBH}$ reaches the $\mathrm{TBH}$, as shown in Figure 2, the hole wall of $\mathrm{TBH}$ will produce larger stress concentration effect under the stress wave which are produced by the $\mathrm{PBH}$.

\section{Model Size and Material Parameters}

For the TSC method, blast holes interval and initiation are arranged without using notching technology, as shown in
Figure 3(a). Initiation at blast hole $A_{1}$ is done first, and the explosion stress wave of blast hole $\mathrm{A}_{1}$ causes stress concentration effect on the hole wall of the blast hole B. Then, the initiation at the blast hole $\mathrm{B}$ is done by the set delay time. Due to the stress superposition effect, crack in the blast hole $\mathrm{B}$ is formed mainly along the direction of the blast hole attachment so as to achieve the crack penetration between blast holes.

Although the control of time interval between successive blast holes can be used to help the TBH to generate cracks extending along the blast hole connection direction, it is impossible to control the initial crack propagation direction of the $\mathrm{PBH} \mathrm{A}_{1}$, which may cause excessive damage to the surrounding rock or the through crack with TBH B cannot be formed. This paper is based on the rock anchor beam layer excavation process of underground powerhouse in the Baihetan hydropower station as the research background [17]. In the blasting excavation of an important structural plane of underground cavern, in order to improve the flatness of cracks between blast holes and reduce the damage degree to the surrounding rock, the $\mathrm{V}$-shaped notch technology is added to the blast holes, but because the time and cost of drilling the notch holes on site are almost twice as much as that of common round holes, only the preblasting holes are grooved, as shown in Figure 3(b).

Using the dynamic finite element method to simulate the rock crack formation mechanism under the TSC method, the $\mathrm{PBH}$ of the TSC method is divided into round hole and notch hole, and the specific model size is as shown in Figure 4. In order to prove that the TSC method can help increase the crack penetrating effect between blast holes, we can increase blast hole spacing gradually to determine a reasonable range, and the specific calculation model is shown in Figure 5.

As shown in Figure 4, some measuring points in the hole wall of TBH are selected to study the stress concentration effect on the empty hole wall of $\mathrm{TBH}$, and the details of the hole wall measuring points of TBH are shown in Figure 6. Notch blast hole size is as shown in Figure 7, and the 


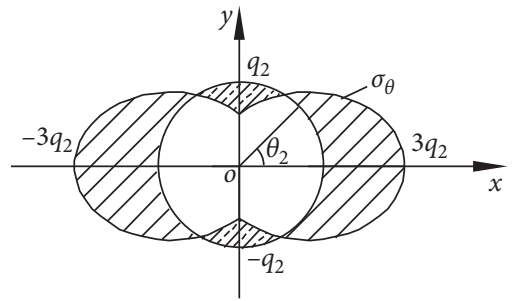

(a)

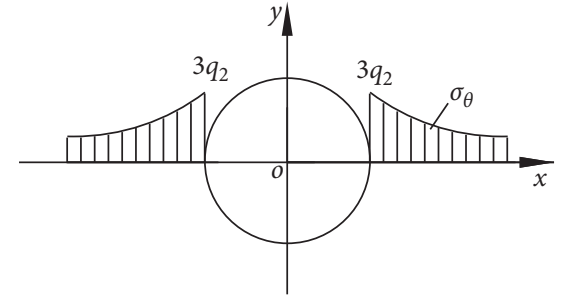

(b)

FIgURE 2: The diagram of stress concentration on the hole wall of the empty hole due to the transverse wave. (a) Hole wall stress. (b) Hole edge stress.

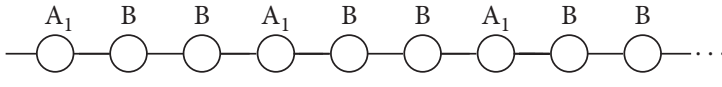

(a)

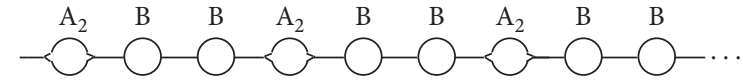

(b)

Figure 3: Blast hole layout diagram. (a) The $\mathrm{PBH}$ is a round hole. (b) The $\mathrm{PBH}$ is a notch hole.

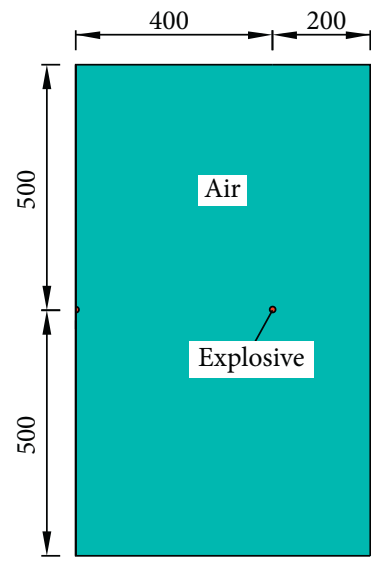

(a)

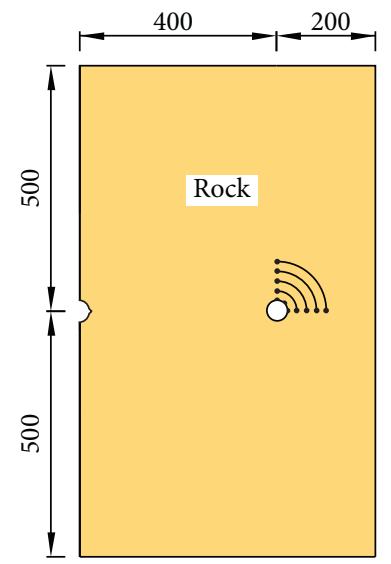

(b)

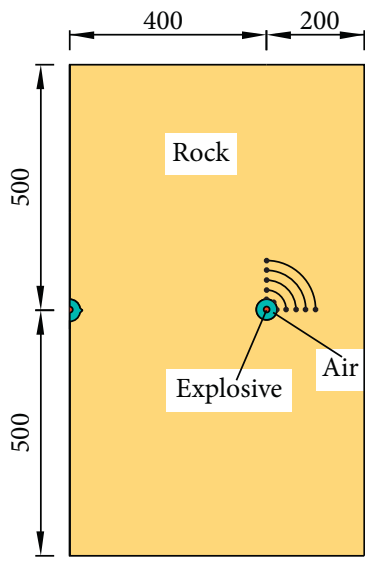

(c)

FIGURE 4: Successive blasting holes spacing is constant. (a) Air and explosive model. (b) Rock model. (c) Complete models of air, explosive, and rock.

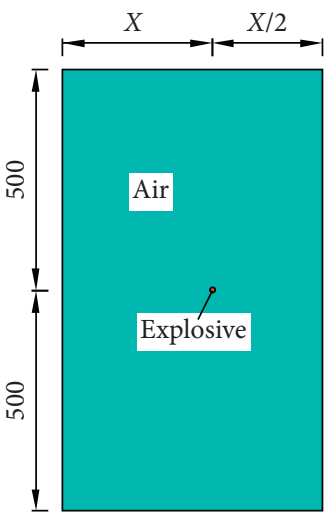

(a)

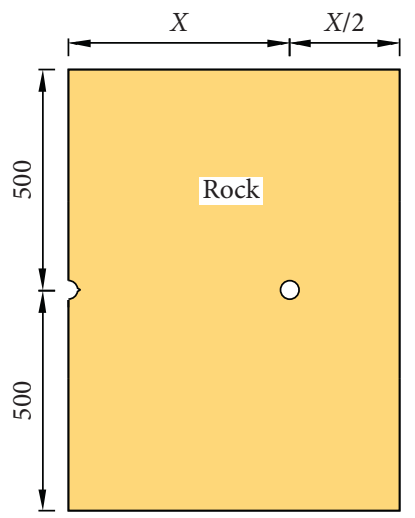

(b)

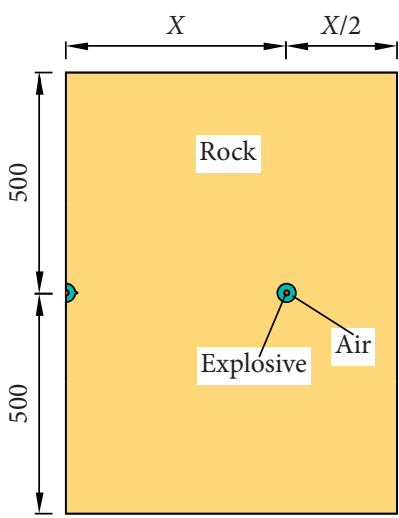

(c)

Figure 5: Successive blasting holes spacing is changed. (a) Air and explosive model. (b) Rock model. (c) Complete models of air, explosive, and rock. 


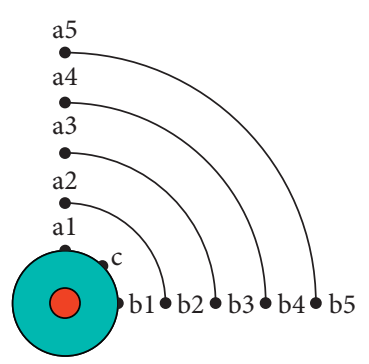

Figure 6: Measuring points arrangement.

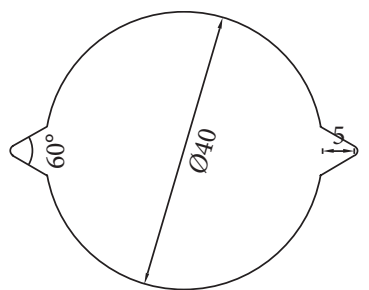

Figure 7: Notch hole size.

notching depth is set as $12 \mathrm{~mm}$ which generally takes the $1 / 8$ of the blast hole diameter. The notching angle is set as $60^{\circ}$ [18] in order to obtain a better oriented result.

Figure 8 shows the explosion load distribution on the notch hole wall. The circular part of blast hole wall has the effect of main pressure, while the notch tip of the blast hole wall has mainly tensile effect.

From Figure 8, it can be seen that the initial explosive pressure on the hole wall of the blast hole is instantaneous, and the tangential tensile stress occurring at notch tip A is due to notch wall pressure. Only when the tangential tensile stress at $\mathrm{A}$ is greater than the tensile strength of rock, can the crack propagate forward along the tip of the notch hole, so the initial crack from element A must satisfy the following equation:

$$
\begin{aligned}
& T>\sigma_{\mathrm{td}}, \\
& T=P_{\mathrm{r}} \cos \left(\frac{\alpha}{2}\right) .
\end{aligned}
$$

In this paper, a semiinfinite body model is adopted, and the dynamic finite element model of follow-up strengthening material is used for calculation. Each model contains three materials: explosive, air, and rock. The cell grid sizes of different material models are basically the same, and the length of the cell grid is $2.5 \mathrm{~mm}$. Each model contains 191,806 cell grids with a blast hole spacing of $400 \mathrm{~mm}$. Detailed meshing diagrams of notch blast holes, round blast holes, and some models are shown in Figure 9.

Explosives and air are defined as multisubstance ALE units, and rock masses are defined as the Lagrange units. The fluid-solid coupling algorithm is defined by adding ALE_MULTI-MATERIAL_GROUP, CONTROL_ ALE, CONSTRAINED_LAGRANGE_IN_SOLID, and other keywords in the calculation program according to Supplementary Materials (available here). The rock mass element node and air element node coincide completely. When the explosive detonates, the explosive energy

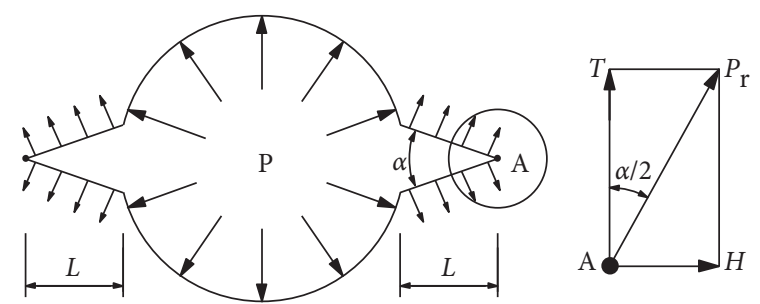

FIgURE 8: Load distribution on hole wall of notch hole.

generated by the explosive can be transmitted directly to the rock mass element node through the air element node, thus causing the dynamic effect of the rock mass element. Nonreflective boundaries are applied on the top of the model, free surfaces are applied on the bottom, vertical constraints are applied on the left and right sides, and vertical constraints are applied on the front and back sides of the model.

ALE mesh advection adopts the second-order algorithm because there are high-performance computer servers in the lab and it can meet the demand of the second order for computing resources. The calculation time of each model is about 1.5 hours. After each time step of calculation, the mesh will not be returned but will continue to calculate in an advection manner.

The JWL state equation can describe the barrel experiment process of the condensed explosive exactly with specific physical significance, so it is generally applied in numerical simulation for blasting. The main chemical components of rock emulsion explosive are ammonium nitrate, sodium nitrate, and water. The JWL [19] state equation of rock emulsion explosive is

$$
P=A\left(1-\frac{w}{R_{1} V}\right) e^{-R_{1} V}+B\left(1-\frac{w}{R_{2} V}\right) e^{-R_{2} V}+\frac{w E_{1}}{V},
$$

where $P$ represents the explosion pressure; $A, B, R_{1}, R_{2}$, and $w$ represent the parameters of the state equation; $V$ represents the relative volume of the detonation gas; and $E_{1}$ represents the specific internal energy.

Some parameters of packaged emulsion explosive and the JWL state equation are as shown in Table 1.

The Grüneisen state equation [21] is applied to describe the air-medium model, and the specific parameters are shown in Table 2.

$$
\begin{aligned}
P= & \frac{\rho_{2} C^{2} \mu\left[1+\left(1-\left(\gamma_{0} / 2\right)\right) \mu-\left(\mu^{2} / 2\right)\right]}{\left[1-\left(S_{1}-1\right) \mu-S_{2}\left(\mu^{2} /(\mu+1)\right)-S_{3}\left(\mu^{3} /(\mu+1)^{2}\right)\right]^{2}} \\
& +\left(\gamma_{0}+a \mu\right) E_{2},
\end{aligned}
$$

where $\rho_{2}$ represents the density of air; $\gamma_{0}$ is the Grüneisen parameter; $C$ represents the curve intercept; $\alpha$ represents the first-order volume correction value of $\gamma_{0} ; S_{1}, S_{2}$, and $S_{3}$ are the coefficients of the curve slope; and $\mu$ represents the volume correction value.

Material parameters of rock mass is derived from the construction bidding documents from civil engineering 


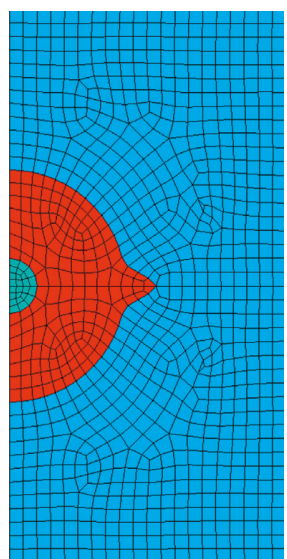

(a)

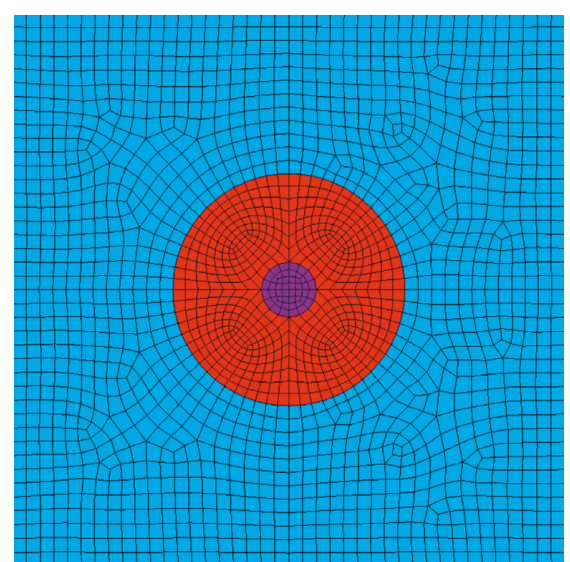

(b)

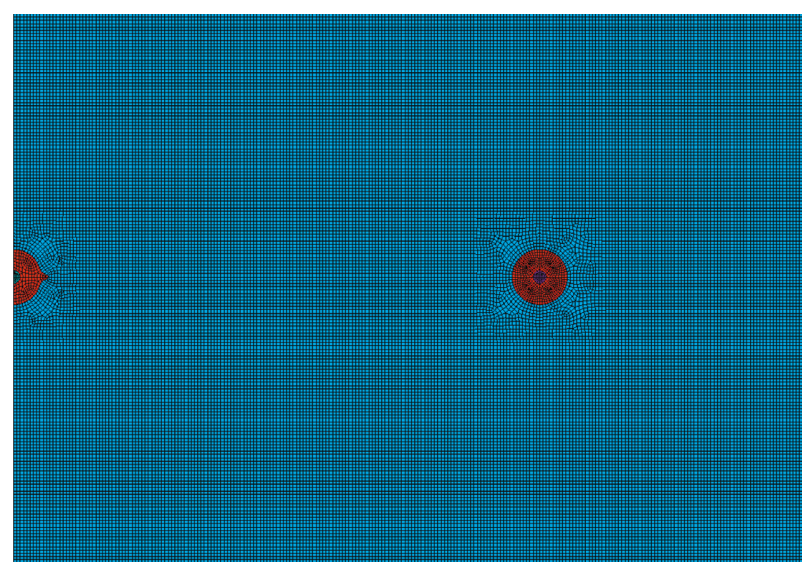

(c)

FIGURE 9: Detailed meshing of explosives, air, and rock mass materials. (a) The notch PBH. (b) The round TBH. (c) Intermediate part model.

TABLE 1: Parameters of the packaged rock emulsion explosive and the JWL state equation [20].

\begin{tabular}{|c|c|c|c|c|c|c|c|}
\hline $\begin{array}{l}\rho_{1} \\
\left(\mathrm{~g} / \mathrm{cm}^{3}\right)\end{array}$ & $\begin{array}{c}D_{0} \\
(\mathrm{~m} / \mathrm{s})\end{array}$ & $A(\mathrm{Gpa})$ & $B$ (Gpa) & $R_{1}$ & $R_{2}$ & $w$ & $E_{1}\left(\mathrm{~J} / \mathrm{m}^{3}\right)$ \\
\hline 1.15 & 3600 & 214 & 0.182 & 4.15 & 0.95 & 0.15 & $4.19 \times 10^{9}$ \\
\hline
\end{tabular}

$\rho_{1}$ represents the density of the explosive; $D_{0}$ represents the detonation velocity.

TABle 2: Material parameters of air [22].

\begin{tabular}{lcccccc}
\hline$\rho_{2}\left(\mathrm{~g} / \mathrm{cm}^{3}\right)$ & $C$ & $S_{1}$ & $S_{2}$ & $S_{3}$ & $\gamma_{0}$ & $E_{2}\left(\mathrm{~J} / \mathrm{m}^{3}\right)$ \\
\hline 0.00125 & 0.344 & 0 & 0 & 0 & 1.4 & 0 \\
\hline
\end{tabular}

and metal structure installation project on the right bank diversion generating system of Jinsha river Baihetan hydropower station, and the parameters are shown in Table 3.

\section{Comparison of Cracks Formation under Different PBH Shapes}

4.1. Stress Concentration Effect on the Blast Hole Wall of TBH under Explosion Stress Wave of $\mathrm{PBH}$. At present, there are no relevant research examples in the practical engineering, so it is difficult to directly prove its rationality from theoretical aspects, and here the method of numerical simulation is adopted first to discuss its feasibility. The model is established as shown in Figure 4. When the $\mathrm{PBH}$ are round blast hole and notch blast hole, respectively, cracks formation effect between blast holes under different blast hole delay time is compared. As shown in Figure 9, the mesh sizes of different material models are basically the same, which can fully reduce the influence of uneven meshing on crack propagation and ensure that cracks between blast holes are mainly expanded under the interaction of explosive stress waves between successive blast holes.

The key parameter of TSC blasting is initiation delay time. Section 2 shows that if we want cracks to extend mainly along
TABle 3: Parameters of rock material.

\begin{tabular}{lcccc}
\hline$\rho_{3}\left(\mathrm{~g} / \mathrm{cm}^{3}\right)$ & $E_{3}(\mathrm{GPa})$ & $G(\mathrm{GPa})$ & $\nu$ & $\sigma_{\mathrm{td}}(\mathrm{MPa})$ \\
\hline 2.7 & 40 & 6.0 & 0.22 & 38.0 \\
\hline
\end{tabular}

$\rho_{3}$ represents the density of rock mass; $E_{3}$ represents the elasticity modulus; $G$ represents the shear modulus; $v$ represents Poisson's ratio; and $\sigma_{\text {td }}$ represents the dynamic tensile strength of rock mass.

the blast hole attachment direction after $\mathrm{TBH}$ initiation, we should initiate TBH after the transverse wave of $\mathrm{PBH}$ has reached the hole wall of $\mathrm{TBH}$, which makes the concentrated stress in the hole wall of TBH along the blast hole attachment direction larger and initial cracks of TBH easily extend along the direction of the blast hole attachment. So the initiation of differential time shall be based on the fact that the transverse wave of $\mathrm{PBH}$ arrives or is just over $\mathrm{TBH}$ :

$$
\Delta t \geq \frac{H}{C}
$$

where $\Delta t$ represents blast hole initiation delay time; $H$ is the space between the $\mathrm{PBH}$ and the $\mathrm{TBH}$; and $C$ represents the velocity of the stress wave.

According to equations (1), (2), and (9), the time taken by the longitudinal wave from the $\mathrm{PBH}$ to the $\mathrm{TBH}$ is $97 \mu \mathrm{s}$ and the time taken by the transverse wave from the $\mathrm{PBH}$ to the $\mathrm{TBH}$ is $268 \mu \mathrm{s}$. In order to determine the optimal time delay between $\mathrm{PBH}$ and $\mathrm{TBH}$, setting the time taken by the longitudinal wave from the $\mathrm{PBH}$ to the $\mathrm{TBH}$ as $t_{\mathrm{p}}$ and the time taken by the transverse wave from the $\mathrm{PBH}$ to the $\mathrm{TBH}$ as $t_{\mathrm{s}}$, it is taken as the multiples of $t_{\mathrm{p}}$ and $t_{\mathrm{s}}$ to set the delay time between $\mathrm{PBH}$ and TBH (p) $1 t_{\mathrm{p}}, 2 t_{\mathrm{p}}, 3 t_{\mathrm{p}}, 4 t_{\mathrm{p}}$, and $5 t_{\mathrm{p}}$; (s) $1 t_{\mathrm{s}}, 2 t_{\mathrm{s}}, 3 t_{\mathrm{s}}, 4 t_{\mathrm{s}}$, and $5 t_{\mathrm{s}}$. The total computation time is $2 \mathrm{~ms}$, and the crack formation diagram is shown in Figure 10.

Previous numerical simulations show that the fracture patterns are almost the same under different mesh topologies $[23,24,25]$. When mesh topology is rectangular, the fracture patterns tend to be linear, which is more convenient for intuitive comparative analysis. When the mesh size of the element is too large, it needs a larger charge quantity of the blast hole to produce the fracture penetration effect, which is 


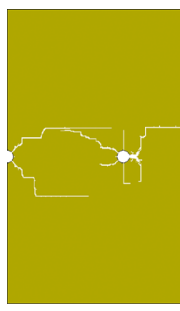

(A) $1 t_{\mathrm{p}}$

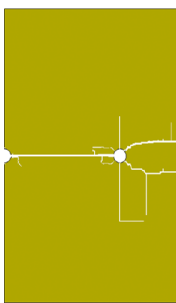

(A) $1 t_{\mathrm{p}}$

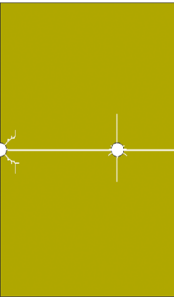

(A) $1 t_{\mathrm{s}}$

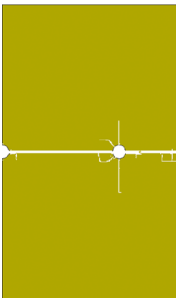

(A) $1 t_{\mathrm{s}}$

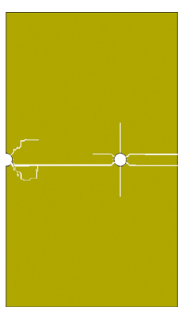

(B) $2 t_{\mathrm{p}}$

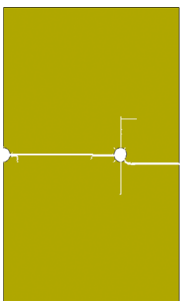

(B) $2 t_{\mathrm{p}}$

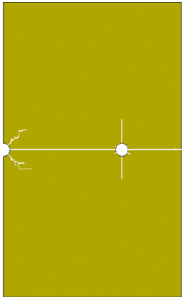

(B) $2 t_{\mathrm{s}}$

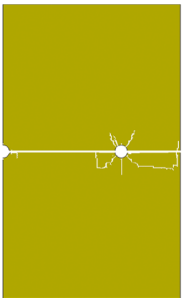

(B) $2 t_{\mathrm{s}}$

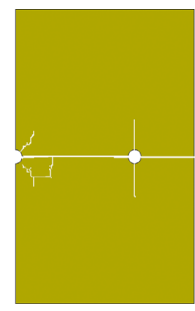

(C) $3 t_{\mathrm{p}}$

(a)

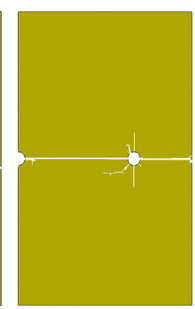

(C) $3 t_{\mathrm{p}}$

(b)

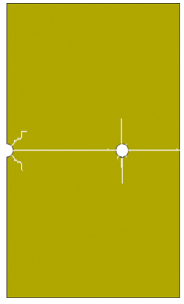

(C) $3 t_{\mathrm{s}}$

(c)

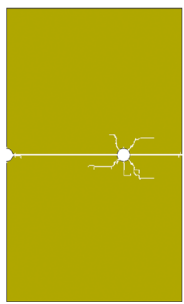

(C) $3 t_{\mathrm{s}}$

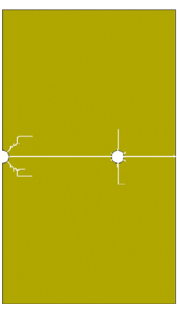

(D) $4 t_{\mathrm{p}}$

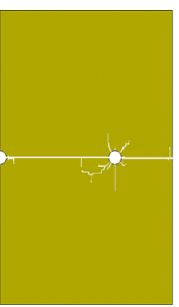

(D) $4 t_{\mathrm{p}}$

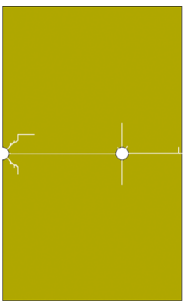

(D) $4 t_{\mathrm{s}}$

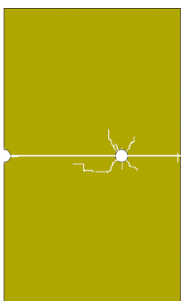

(D) $4 t_{\mathrm{s}}$

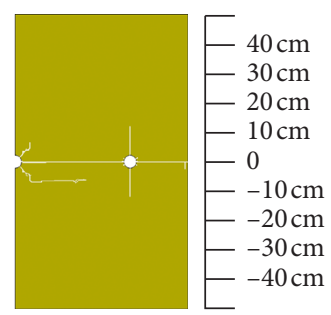

(E) $5 t_{\mathrm{p}}$

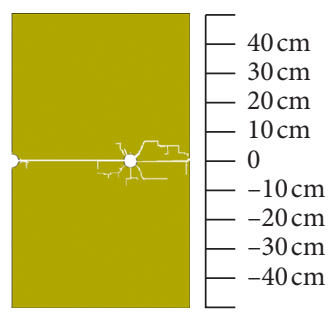

(E) $5 t_{\mathrm{p}}$

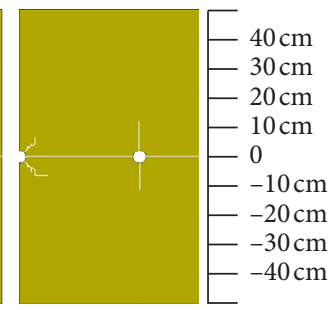

(E) $5 t_{\mathrm{s}}$

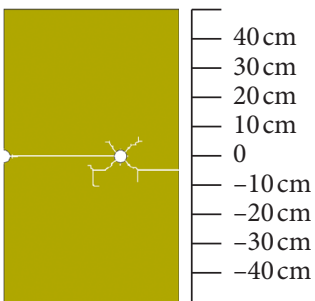

(E) $5 t \mathrm{~s}$

(d)

FIGURE 10: Crack formation diagram for different PBH shapes and different delay time. (a) The PBH is a round hole, different longitudinal wave multiples. (b) The PBH is a notch hole, different longitudinal wave multiples. (c) The PBH is a round hole, different transverse wave multiples. (d) The PBH is notch hole, different transverse wave multiples.

not in-line with the actual situation. When the mesh size is too small, many small branch fractures are generated, and the main fracture pattern is still consistent with the fracture formation state in Figure 10, but the calculation time is greatly increased, so the mesh topology adopted in this paper is reasonable.

From Figure 10, it can be seen that (1) the surrounding rock still has an obvious phenomenon of over dig or little dig when delay time between $\mathrm{PBH}$ and TBH is $1 t_{\mathrm{p}}$ and $2 t_{\mathrm{p}}$. When delay time $\Delta t \geq 3 t_{\mathrm{p}}$, though the surrounding rock has some damage caused by explosive shock, a straight crack is formed along the blast hole attachment. (2) When the delay time is taken as the multiples of $t_{\mathrm{s}}$, through crack can be formed along the blast hole attachment direction under any delay time.

Research shows that if the delay time between PBH and TBH $\Delta t<t_{\mathrm{s}}$, cracks cannot be formed between adjacent blast holes when PBH is a round hole; when PBH is a notch hole, a straight crack can be formed between notch hole and round hole because the notch hole can guide explosive energy, but through cracks cannot be formed between adjacent TBH. If the delay time between $\mathrm{PBH}$ and TBH $\Delta t \geq t_{\mathrm{s}}$, through cracks can be formed along the blast hole attachment under the given delay time of the blast holes. Even if the $\mathrm{PBH}$ is a round 
hole or notch hole, it is stated that initial cracks of TBH easily extend along the blast hole attachment when the delay time $\Delta t \geq t_{\mathrm{s}}$ because of tensile stress effect of the transverse wave caused by $\mathrm{PBH}$.

Setting the delay time $2 t_{\mathrm{p}}$ and $2 t_{\mathrm{s}}$ as constant, namely, $\Delta t=194 \mu \mathrm{s}, 536 \mu \mathrm{s}$, the stress values of the hole wall of $\mathrm{TBH}$ under different $\mathrm{PBH}$ shapes are compared. According to Figure 6 , the center of $\mathrm{TBH}$ is taken as the circle, and eleven elements are taken in the ring with a radius of $2 \mathrm{~cm}, 4 \mathrm{~cm}$, $6 \mathrm{~cm}, 8 \mathrm{~cm}$, to $10 \mathrm{~cm}$ to conduct comparative analysis in three aspects: (1) change in the tangential stress for different elements perpendicular to the direction of the blast hole connection; (2) change in the tangential stress for elements along the direction of the blast hole connection; and (3) change in the tangential stress for the points on the blast hole wall at different angles. The graph of stress at specific elements is shown in Figures 11 and 12.

From Figure 11, the following conclusion can be obtained: (1) the hole wall elements of TBH is only affected by the longitudinal wave of $\mathrm{PBH}$ when the delay time is $194 \mu \mathrm{s}$ and the tangential tensile stress at the measuring point al in the hole wall is about three times the value of stress at measuring points a2, a3, a4, and a5, which is consistent with Yang's conclusion. (2) Element along the blast hole attachment of $\mathrm{TBH}$ is consistent with the longitudinal wave propagation direction, and only stress concentration occurs on the blast hole wall, so it does not meet Yang's conclusion. (3) The tangential tensile stress of the measuring points a1 and b1 are larger than $c$. It shows that the tangential tensile stress of elements in the perpendicular direction to the hole line and along the direction of the hole line is larger than that of other directions caused by the longitudinal wave of $\mathrm{PBH}$.

When the delay time is $536 \mu \mathrm{s}$, the longitudinal wave and transverse wave of $\mathrm{PBH}$ have reached $\mathrm{TBH}$ before $\mathrm{TBH}$ initiation. From Figure 9, it can be seen that (1) even if the $\mathrm{PBH}$ is a round hole or notch hole, the stress value of blast hole wall elements of $\mathrm{TBH}$ a1-a5 and b1-b5 is basically the same as per Yang's conclusion and the elements al and b1 of the blast hole wall can produce stress concentration effect, but $\mathrm{a} 2-\mathrm{a} 5$ and $\mathrm{b} 2-\mathrm{b} 5$ cannot produce stress concentration phenomenon, which is the same as the Saint-Venant principle. (2) After the transverse wave of $\mathrm{PBH}$ has arrived $\mathrm{TBH}$, the tangential tensile stress of the $\mathrm{TBH}$ hole wall elements along the blast hole attachment direction is larger than that when delay time is $194 \mu \mathrm{s}$, and when $\mathrm{PBH}$ is a notch hole, the hole wall of TBH basically has the tangential tensile stress and cracks are mostly easily extended along blast hole attachment after TBH initiation. (3) The tangential tensile stress of the measuring points a1 and b1 are larger than that of $c$ when $\mathrm{PBH}$ is a round hole, and the tangential tensile stress of measuring points $\mathrm{b} 1$ and $\mathrm{c}$ are larger than that of al when $\mathrm{PBH}$ is a notch hole. From the discussion above, it can be found that cracks are more easily extended along the blast hole attachment direction when $\mathrm{PBH}$ is a notch hole.

The shape of $\mathrm{PBH}$ can influence the propagation of energy and direction of explosion stress wave, and comparison of the stress value of TBH hole wall elements a1 and b1 under different PBH shapes is shown in Figure 13. When the delay time is $194 \mu \mathrm{s}$, though the change rule of tangential tensile stress of element a1 is similar under different $\mathrm{PBH}$ shapes, the tangential tensile stress value of element al in the notch $\mathrm{PBH}$ is larger than that in the round $\mathrm{PBH}$. The peak value of tangential tensile stress of element b1 is similar under different $\mathrm{PBH}$ shapes, which is less affected by the $\mathrm{PBH}$ shape. It shows that, when $\mathrm{PBH}$ is a notch hole, the hole wall of $\mathrm{TBH}$ will produce larger tangential tensile stress under the longitudinal wave effect of $\mathrm{PBH}$.

When delay time is $536 \mu \mathrm{s}$, there is larger tangential tensile stress of elements al and b1 due to the effect of the longitudinal wave and transverse wave of $\mathrm{PBH}$ hole wall on TBH. From Figure 13, it can be seen that both the tangential tensile stress values of elements al and b1 in the notch $\mathrm{PBH}$ are larger than that in the round $\mathrm{PBH}$. It shows that the notch hole directs more explosive energy to the $\mathrm{TBH}$, thus making the concentrated stress of the $\mathrm{TBH}$ hole wall greater. The following stress nephogram shows the surrounding stress state before TBH initiation, as shown in Figure 14.

From Figure 14, it can be seen that, when $\mathrm{PBH}$ is a round hole, the stress in the whole model is uniformly distributed and the concentrated stress of the hole wall of $\mathrm{TBH}$ is small. When $\mathrm{PBH}$ is a notch hole, through crack has been formed between $\mathrm{PBH}$ and $\mathrm{TBH}$ before $\mathrm{TBH}$ initiation and there is obvious tensile stress concentration region in the right side of the hole wall of TBH. Therefore, the tangential tensile stress of elements b1 and c is relatively larger, which is more conducive to the formation of through cracks between adjacent $\mathrm{TBH}$.

4.2. Stress Concentration Effect of TBH Wall under Millisecond Delay. From Figure 10, it can be seen that, whether the $\mathrm{PBH}$ is a notch hole or round hole, through cracks can basically be formed between blast holes when delay time $\Delta t \geq t_{\mathrm{s}}$, and the damage depth of surrounding rock is less than $10 \mathrm{~cm}$. Now the existing electric detonator can only achieve millisecond delay [26], and in order to combine research contents with practical engineering, the delay time between $\mathrm{PBH}$ and $\mathrm{TBH}$ will be increased to millisecond level. The blast hole delay time is set to be $1 \mathrm{~ms}, 2 \mathrm{~ms}, 3 \mathrm{~ms}$, and $4 \mathrm{~ms}$, respectively, and the corresponding total calculation time of model is $2 \mathrm{~ms}, 3 \mathrm{~ms}, 4 \mathrm{~ms}$, and $5 \mathrm{~ms}$, respectively. Cracks formation diagram within total calculation time is shown in Figure 15.

From Figure 15, it can be seen that, when $\mathrm{PBH}$ is a round hole, through cracks can be formed when delay time is $1 \mathrm{~ms}$ and $2 \mathrm{~ms}$, but the concentrated stress effect is reduced so that through cracks cannot be formed when delay time is $3 \mathrm{~ms}$ and $4 \mathrm{~ms}$. When $\mathrm{PBH}$ is a notch hole, through cracks can always be formed under different delay time. It shows that notch $\mathrm{PBH}$ can not only form through cracks between $\mathrm{PBH}$ and $\mathrm{TBH}$ but also contribute to form cracks between adjacent TBH. The setting delay time $1 \mathrm{~ms}$ and $3 \mathrm{~ms}$ is taken as example, and the stress change analysis of elements a1, b1, and $c$ in the hole wall of TBH is shown in Figures 16 and 17.

It can be seen from Figure 16 that, when delay time is $1 \mathrm{~ms}$, if $\mathrm{PBH}$ is a round hole, the stress value of the hole wall element satisfies the relation $\mathrm{b} 1>\mathrm{a} 1>\mathrm{c}$ before $\mathrm{TBH}$ initiation; if $\mathrm{PBH}$ is a notch hole, the stress value of hole wall element satisfies the relation $\mathrm{b} 1>\mathrm{c}>\mathrm{b} 1$ before $\mathrm{TBH}$ 


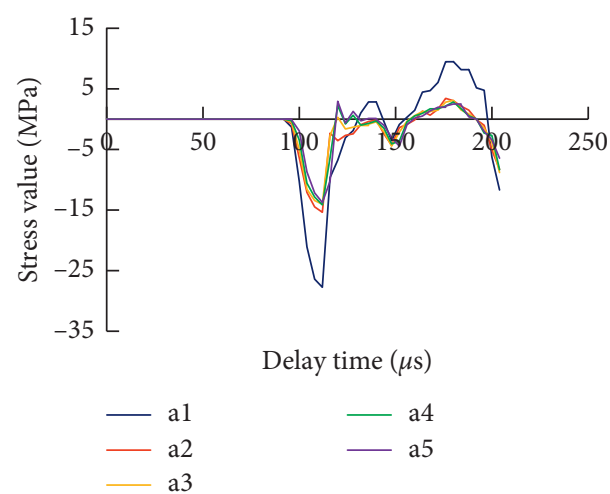

(a)

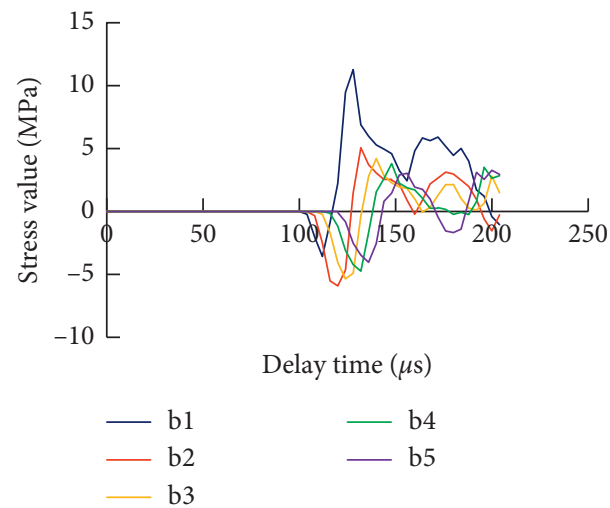

(c)

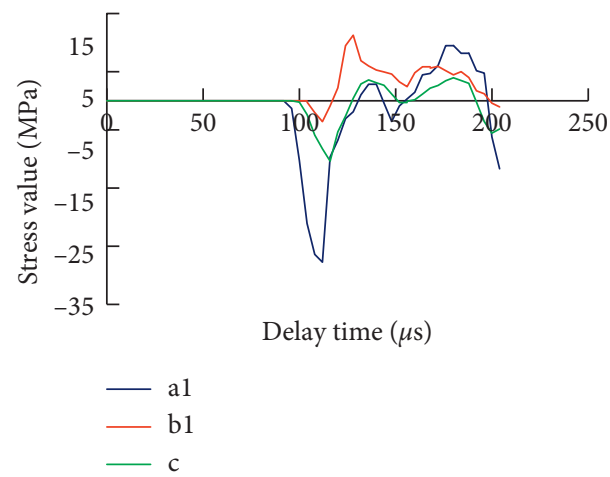

(e)

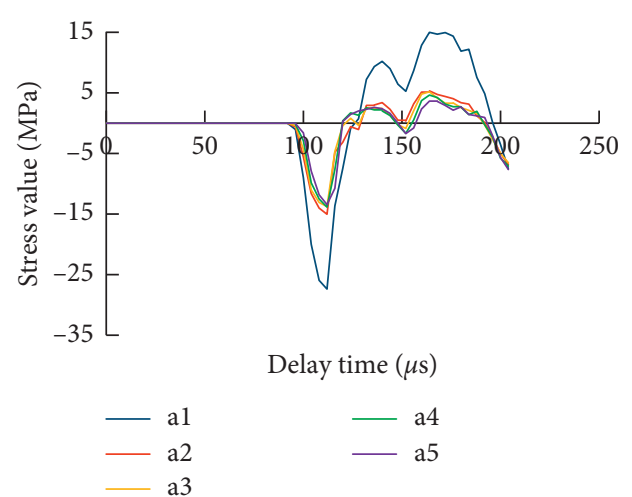

(b)

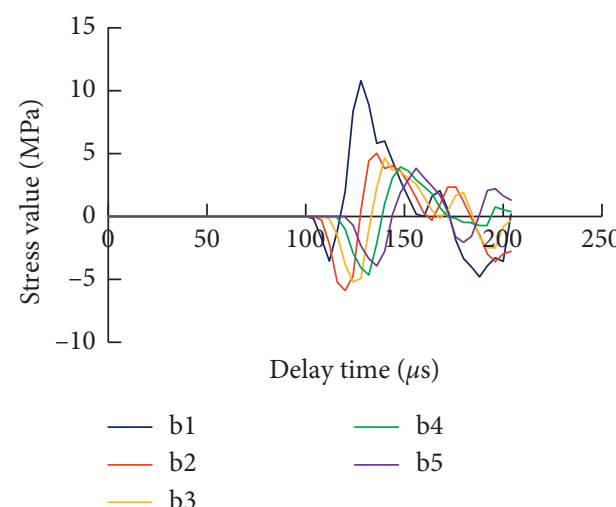

(d)

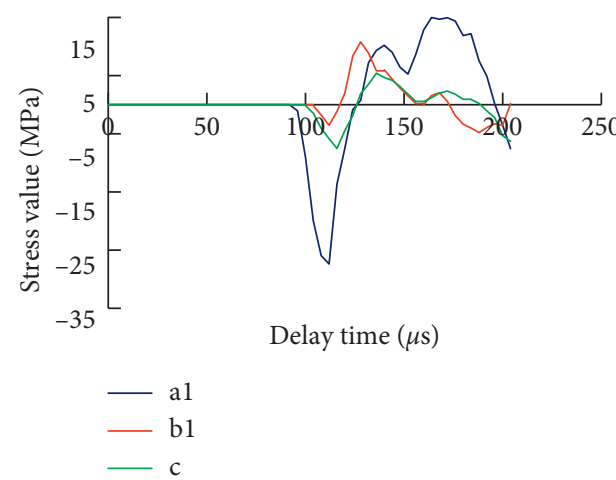

(f)

Figure 11: Elements of the TBH wall stress concentrate curve before TBH initiation when the delay time is $194 \mu \mathrm{s}$. (a, c, e) The PBH is a round hole. $(b, d, f)$ The $\mathrm{PBH}$ is a notch hole.

initiation. It can be found that no matter what shape the $\mathrm{PBH}$ is, the stress value of hole wall element b1 is the biggest, so initial cracks can easily be extended along the direction of element b1 after TBH initiation, and through crack is formed between adjacent blast holes and hence can achieve good effect of smooth blasting excavation.

When the delay time is $3 \mathrm{~ms}$ and $\mathrm{PBH}$ is a round hole, the stress value of element b1 is relatively larger than that of elements a1 and c, but because the whole stress value of elements is too small, the explosion effect of TBH initiation in time $3 \mathrm{~ms}$ is similar to single hole blasting, and finally it fails to use the superposition effect of the explosion stress wave between blast holes to form through cracks along the blast hole attachment direction. When PBH is a notch hole, although the stress concentration effect is gradually weakened when TBH approaches the initiation, elements a1, b1, and $\mathrm{c}$ are always retaining a state of tension. Cracks would extend along the tensile region of rock. It is proved that notch $\mathrm{PBH}$ not only plays a guiding role for explosive energy but also helps retaining concentrated stress for longer time in the hole wall of TBH.

4.3. Analysis of Crack Formation under Different Blast Hole Spacings. According to the results of the above analysis, in order to determine the maximum blast hole spacing under 


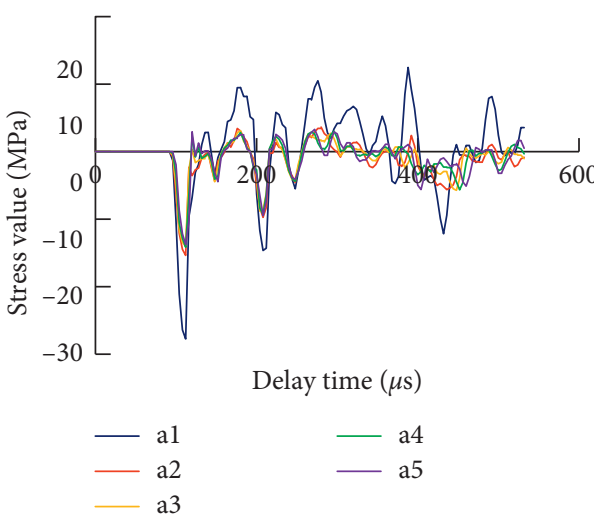

(a)

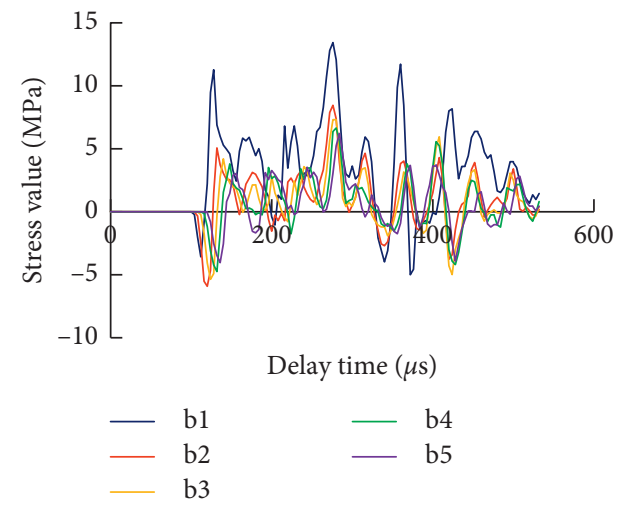

(c)

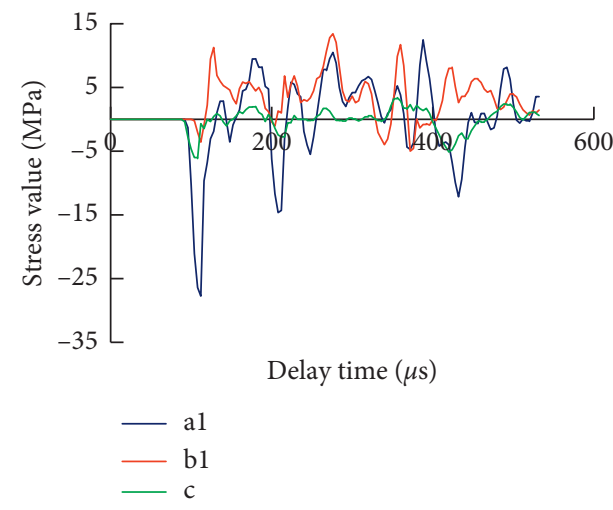

(e)

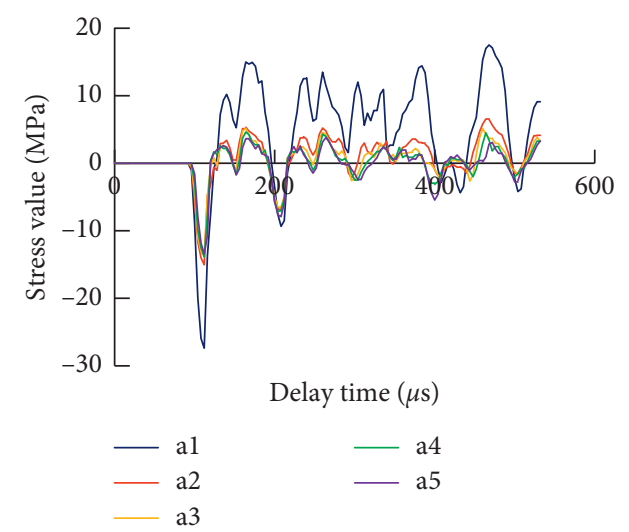

(b)

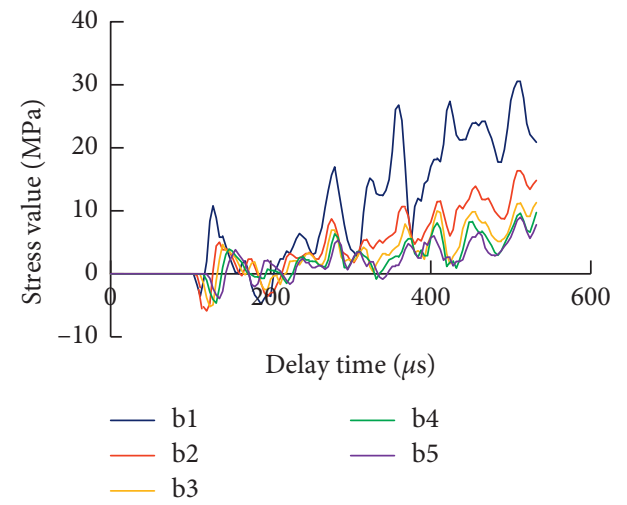

(d)

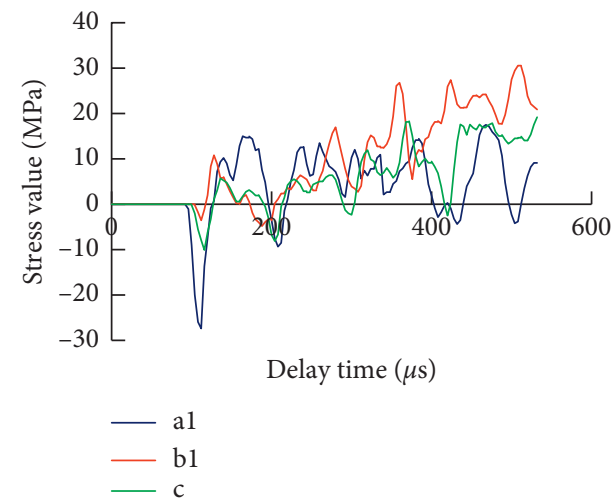

(f)

FIgURE 12: Stress concentration curve of elements of the TBH wall before TBH initiation when the delay time is $536 \mu$ s. (a, c, e) The PBH is a round hole. $(b, d, f)$ The $\mathrm{PBH}$ is a notch hole.

delay time of initiation, blast hole spacing is increased to $50 \mathrm{~cm}, 60 \mathrm{~cm}, 70 \mathrm{~cm}, 80 \mathrm{~cm}, 90 \mathrm{~cm}, 100 \mathrm{~cm}, 110 \mathrm{~cm}$, and $120 \mathrm{~cm}$ and comparative analysis of the cracks formation under different blast hole spacing is done. The corresponding time of the transverse wave from $\mathrm{PBH}$ to $\mathrm{TBH}$ is, respectively, $335 \mu \mathrm{s}, 402 \mu \mathrm{s}, 470 \mu \mathrm{s}, 536 \mu \mathrm{s}, 604 \mu \mathrm{s}, 671 \mu \mathrm{s}$, $738 \mu \mathrm{s}$, and $0804 \mu \mathrm{s}$, and all of this calculated delay time is less than $1000 \mu \mathrm{s}$. From Section 4, it can be known that the delay time between $\mathrm{PBH}$ and $\mathrm{TBH} \Delta t \geq t_{\mathrm{s}}$ is the stress condition for through cracks to be formed. In order to avoid the delay time from being too long and to make the stress wave attenuation too much, in the following section, the delay time is taken as $1 \mathrm{~ms}$ and the total computing time is $2 \mathrm{~ms}$. And finally cracks formation diagrams under different PBH shapes are shown in Figures 18 and 19.

It can be seen from Figure 18 that, when $\mathrm{PBH}$ is a round hole, through cracks can be formed along the blast hole attachment direction when the blast hole spacing is 50$70 \mathrm{~cm}$, and the damage depth of the surrounding rock is almost $10 \mathrm{~cm}$; but through cracks cannot be formed when the blast hole spacing is $80-120 \mathrm{~cm}$. It shows that both the concentrated stress effect of $\mathrm{TBH}$ and the stress superposition effect between $\mathrm{PBH}$ and $\mathrm{TBH}$ are decreasing with the increase of blast hole spacing, so the through cracks cannot 


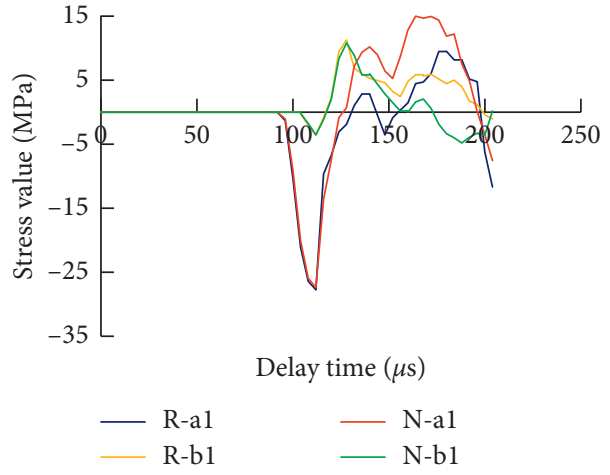

(a)

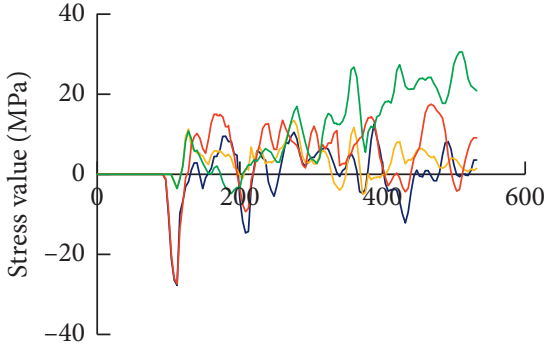

Delay time $(\mu \mathrm{s})$

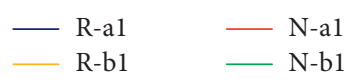

(b)

FIGURE 13: Stress concentration curve of elements al and b1 of TBH wall before TBH initiation for different PBH shapes. (a) Delay time $194 \mu \mathrm{s}$. (b) Delay time $536 \mu \mathrm{s}$.

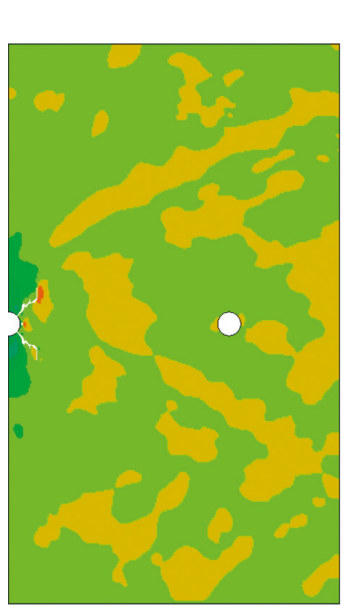

(a)

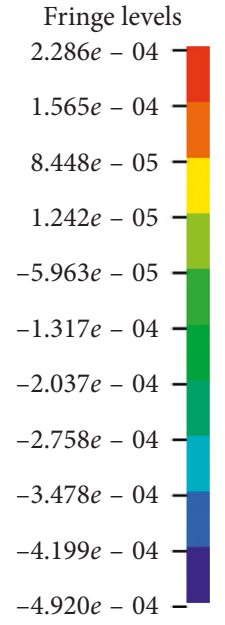

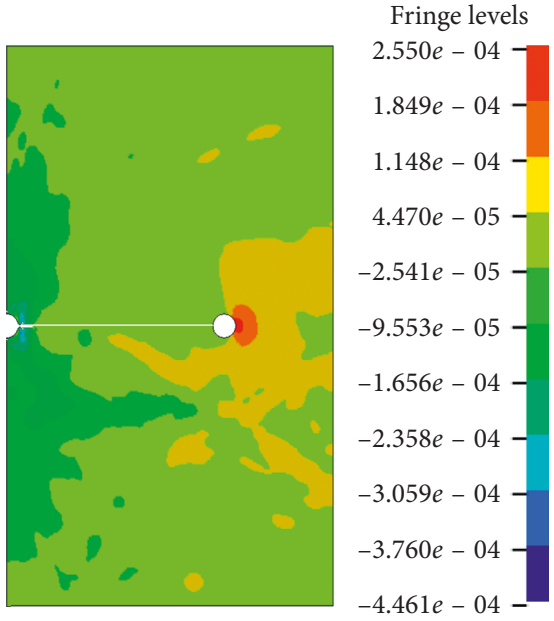

(b)

FIgure 14: The tangential tensile stress nephogram at the time of $536 \mu$ s (unit: $10^{11} \mathrm{pa}$ ). (a) The PBH is a round hole. (b) The PBH is a notch hole.

be formed along blast hole attachment direction. It shows that when $\mathrm{PBH}$ and $\mathrm{TBH}$ are round holes and blast hole, the delay time is $1 \mathrm{~ms}$, and through cracks can be formed along the blast hole attachment direction under blast hole spacing $H_{\mathrm{R}} \leq 17.5 d$ ( $d$ is the blast hole diameter).

From Figure 19, it can be seen that, when $\mathrm{PBH}$ is a notch hole, through cracks can be formed along blast hole attachment direction when the blast hole spacing is $50-100 \mathrm{~cm}$ and the damage depth of the surrounding rock is also almost $10 \mathrm{~cm}$. Although through cracks can be formed between $\mathrm{PBH}$ and TBH when the blast hole spacing is $110-120 \mathrm{~cm}$, through cracks cannot be formed between adjacent $\mathrm{TBH}$, obvious lack dig phenomenon occurs, and the damage depth of surrounding rock is almost $30 \mathrm{~cm}$. It shows that when $\mathrm{PBH}$ is a notch hole, $\mathrm{TBH}$ is a round hole, and blast hole delay time is $1 \mathrm{~ms}$, through cracks can be formed along blast hole attachment direction under blast hole spacing $H_{\mathrm{R}} \leq 25 \mathrm{~d}$.

For more specific analysis of the stress concentration effect of $\mathrm{TBH}$ hole wall element b1 before $\mathrm{TBH}$ initiation, comparative analysis of the stress value of element b1 under different blast hole spacing and different $\mathrm{PBH}$ shapes before $\mathrm{TBH}$ initiation is done.

From the stress curve diagram of element b1 in Figure 20, it can be seen that (1) the stress change rule of element b1 is similar when $\mathrm{PBH}$ is a round hole and the stress value decreases with the blast hole spacing increases. (2) When $\mathrm{PBH}$ is a notch hole and blast hole spacing is 50$100 \mathrm{~cm}$, the tangential tensile stress of $\mathrm{TBH}$ hole wall element b1 increases suddenly from a certain time. It shows that through cracks have been formed between $\mathrm{PBH}$ and TBH before TBH initiation, so initial crack is easily extended along near element b1. When blast hole spacing is 110$120 \mathrm{~cm}$, the tangential tensile stress of TBH hole wall element b1 does not increase. It shows that through cracks have not been formed between $\mathrm{PBH}$ and TBH before TBH initiation, the explosion stress wave from $\mathrm{PBH}$ to $\mathrm{TBH}$ has a bigger attenuation, and the advantage of stress concentration effect of element b1 basically disappears. Hence through cracks cannot be formed along the blast hole attachment between adjacent TBHs. 


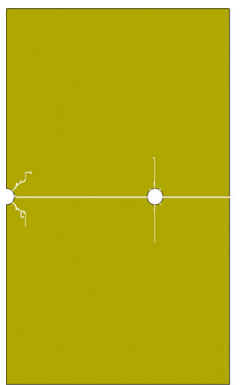

(A) $\Delta t=1 \mathrm{~ms}$

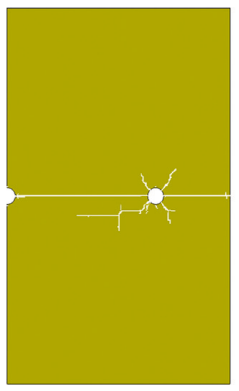

(A) $\Delta t=1 \mathrm{~ms}$

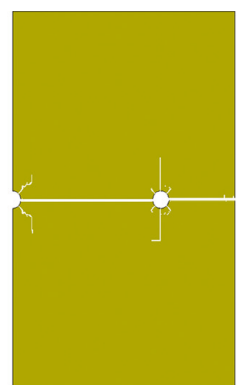

(B) $\Delta t=2 \mathrm{~ms}$

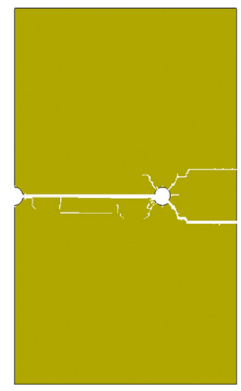

(B) $\Delta t=2 \mathrm{~ms}$

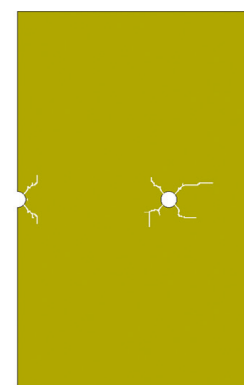

(C) $\Delta t=3 \mathrm{~ms}$

(a)

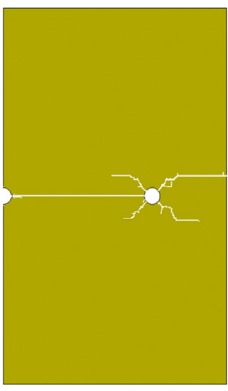

(C) $\Delta t=3 \mathrm{~ms}$

(b)

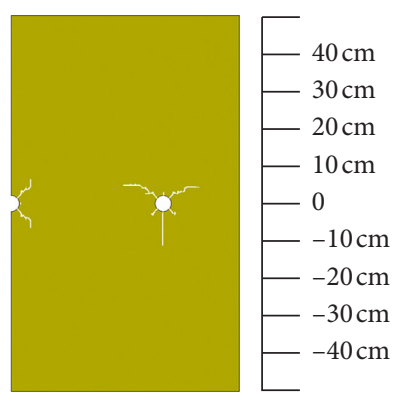

(D) $\Delta t=4 \mathrm{~ms}$

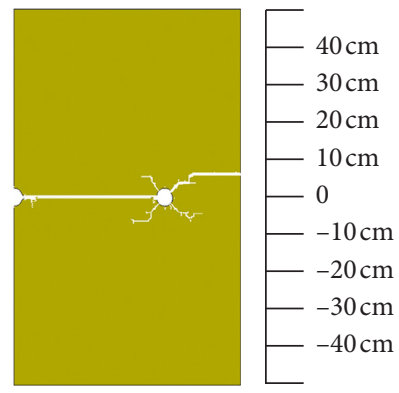

(D) $\Delta t=4 \mathrm{~ms}$

Figure 15: Crack formation diagram under different PBH shapes and different delay time. (a) The PBH is a round hole. (b) The PBH is a notch hole.

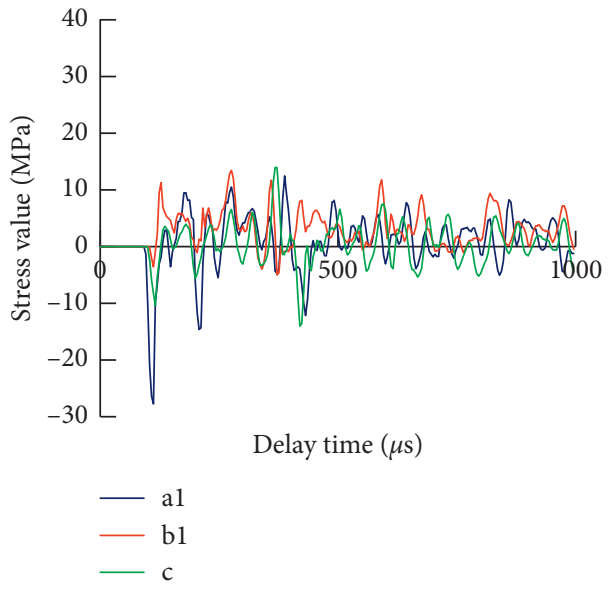

(a)

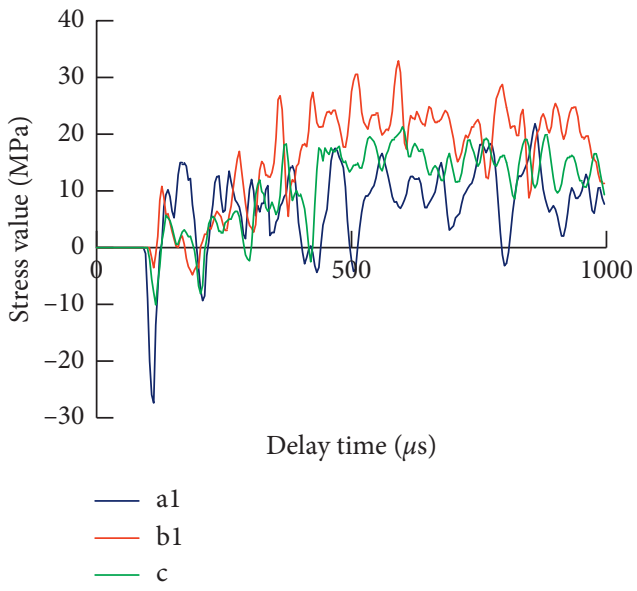

(b)

FIgURE 16: Stress concentrate curve of elements of TBH hole wall before TBH initiation when delay time is $1 \mathrm{~ms}$. (a) The PBH is a round hole. (b) The PBH is a notch hole.

Therefore, when $\mathrm{PBH}$ is a notch hole, it not only decreases the damage depth of surrounding rock but also increases the blast hole spacing to improve the efficiency of smooth blasting excavation.

\section{Conclusion}

For the analysis of delay in blast hole initiation, the $\mathrm{PBH}$ is divided into round hole and notch hole. By means of numerical simulation, the crack formation diagrams of different shapes of $\mathrm{PBH}$ with different blast hole delay time under the same blast hole spacing are compared. Then the crack formation diagrams of different shapes of $\mathrm{PBH}$ with same blast hole delay time under the different blast hole spacing are compared. Then the following conclusions were obtained:

(1) If the delay time between $\mathrm{PBH}$ and $\mathrm{TBH}$ is $\Delta t<t_{\mathrm{s}}$, straight through cracks cannot be formed between 


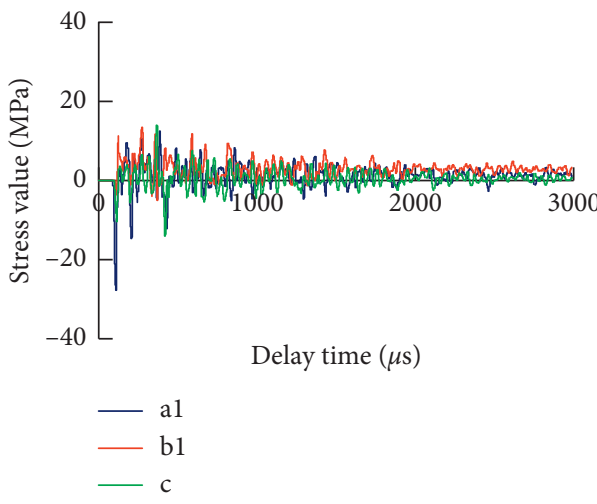

(a)

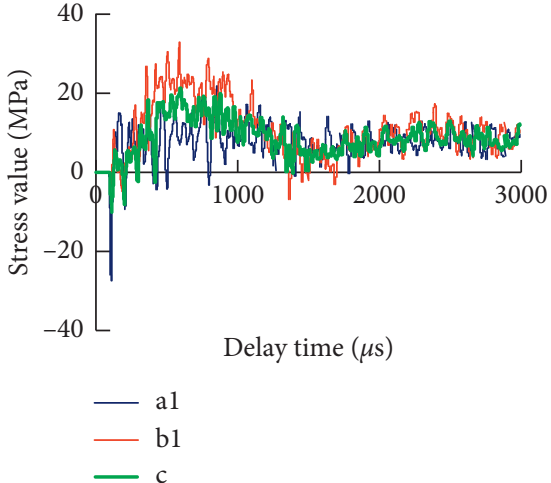

(b)

FIgURE 17: Stress concentration curve of elements of TBH hole wall before TBH initiation when the delay time is $3 \mathrm{~ms}$. (a) The PBH is a round hole. (b) The PBH is a notch hole.

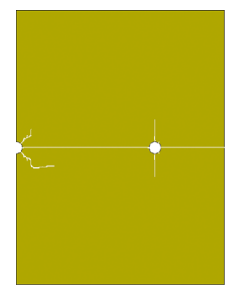

(a)

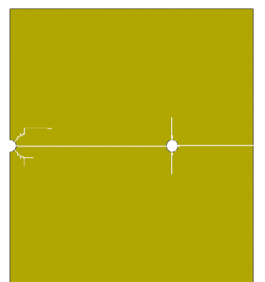

(b)

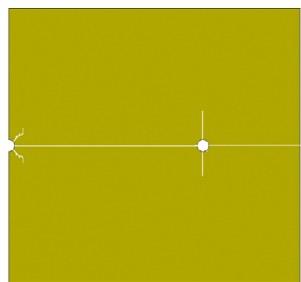

(c)

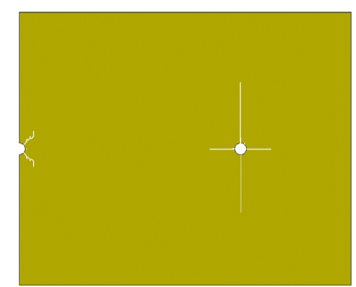

(d)

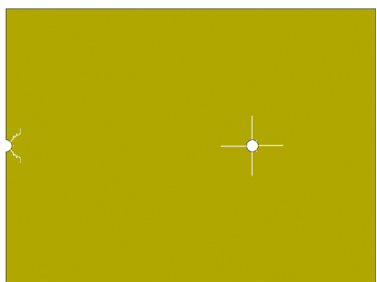

(e)

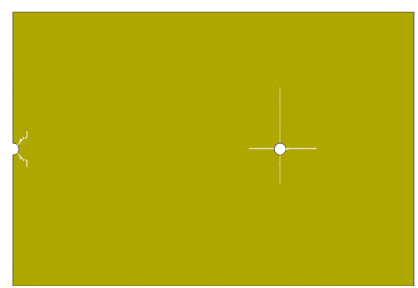

(f)

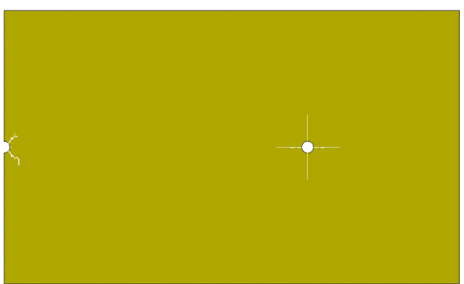

(g)

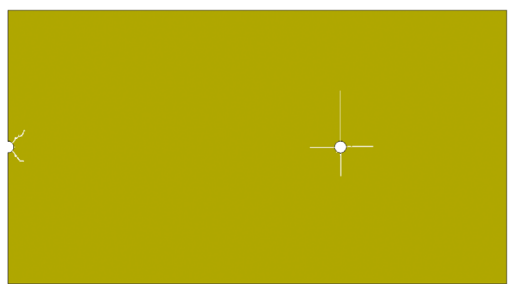

(h)

FIGURE 18: Cracks formation diagram under different blast hole spacing when $P B H$ is a round hole. (a) $H=50 \mathrm{~cm}$. (b) $H=60 \mathrm{~cm}$. (c) $H=70 \mathrm{~cm}$. (d) $H=80 \mathrm{~cm}$. (e) $H=90 \mathrm{~cm}$. (f) $H=100 \mathrm{~cm}$. (g) $H=110 \mathrm{~cm}$. (h) $H=120 \mathrm{~cm}$.

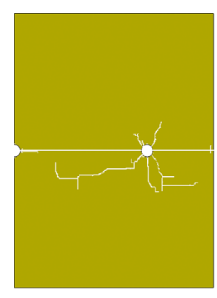

(a)

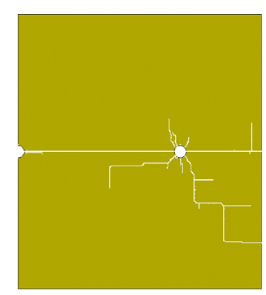

(b)

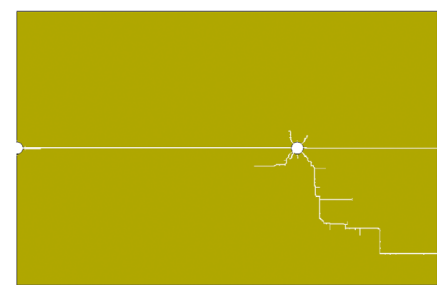

(f)

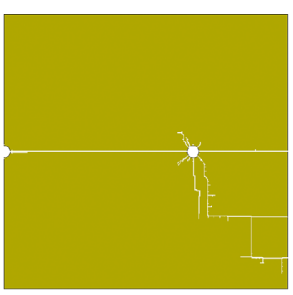

(c)

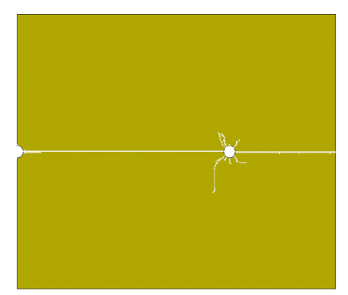

(d)

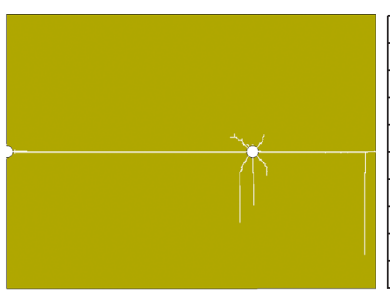

(e)

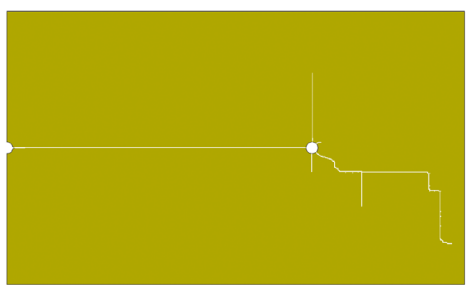

(g)

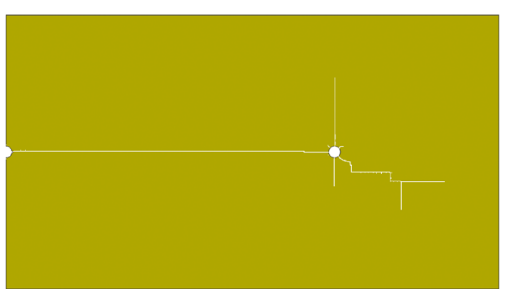

(h)
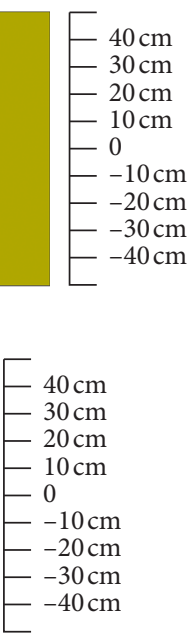


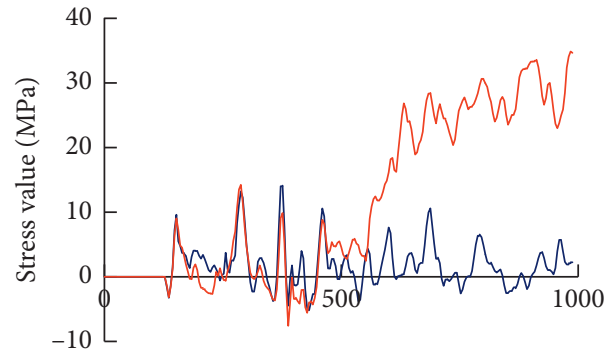

Delay time $(\mu \mathrm{s})$

— Round hole

— Notch hole

(a)

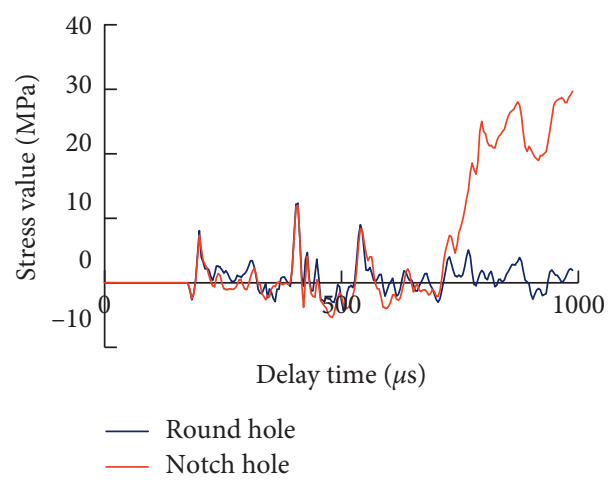

(c)

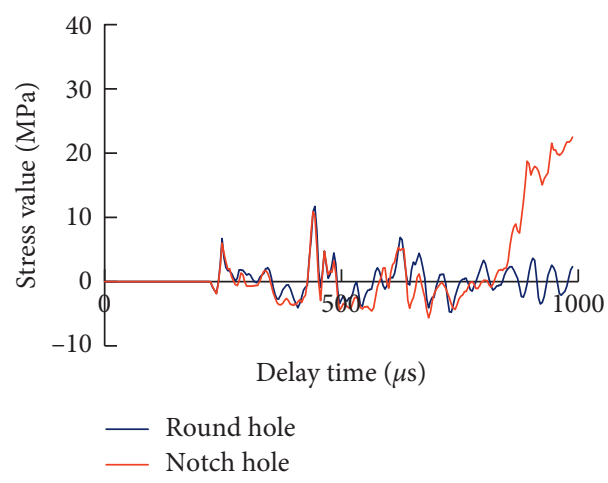

(e)

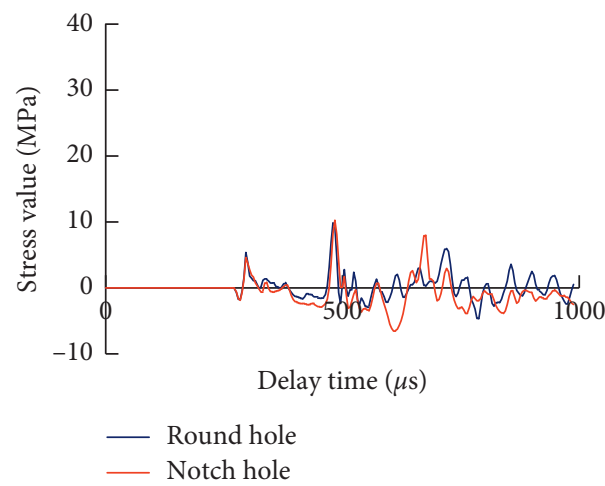

(g)

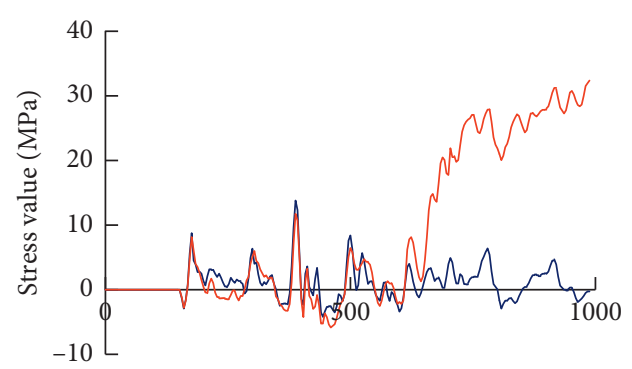

Delay time $(\mu \mathrm{s})$

_ Round hole

— Notch hole

(b)

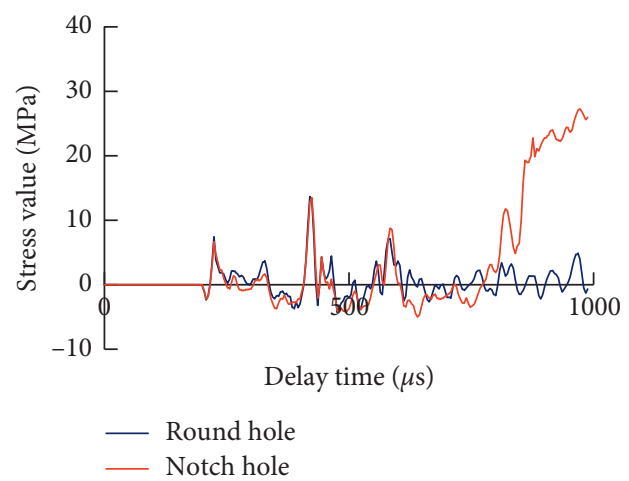

(d)

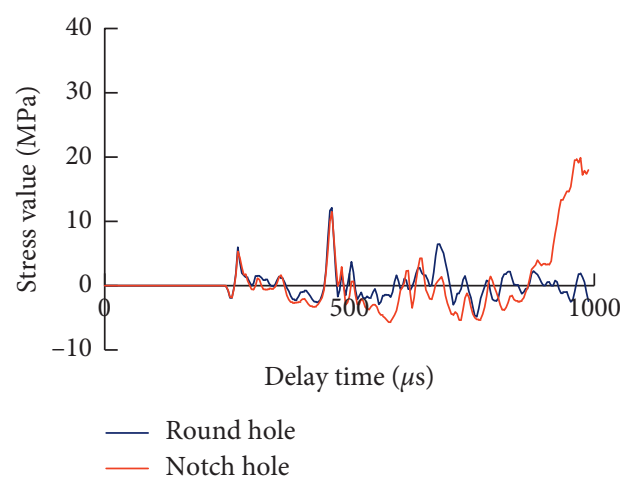

(f)

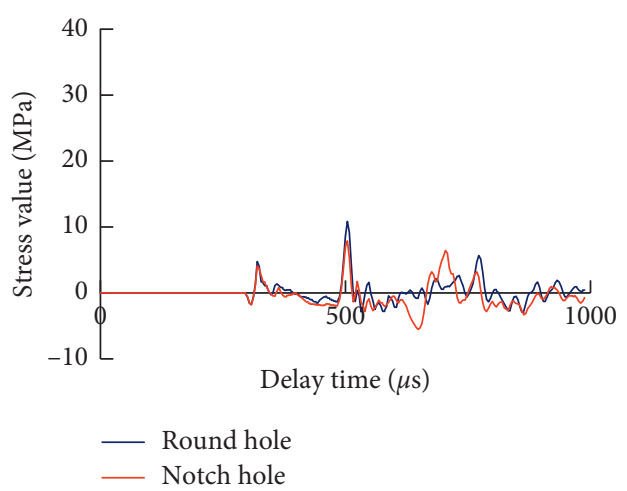

(h)

FIgURe 20: The stress curve of TBH hole wall measuring element b1 before TBH initiation. (a) $H=50 \mathrm{~cm}$. (b) $H=60 \mathrm{~cm}$. (c) $H=70 \mathrm{~cm}$. (d) $H=80 \mathrm{~cm}$. (e) $H=90 \mathrm{~cm}$. (f) $H=100 \mathrm{~cm}$. (g) $H=110 \mathrm{~cm}$. (h) $H=120 \mathrm{~cm}$. 
successive blast holes. If the delay time between $\mathrm{PBH}$ and $\mathrm{TBH}$ is $\Delta t \geq t_{\mathrm{s}}$, through cracks can be formed along the blast hole attachment, so the delay time should be based on the arrival time of transverse wave of $\mathrm{PBH}$ to $\mathrm{TBH}$.

(2) When the blast hole spacing is $H=10 \mathrm{~d}$, compared with round $\mathrm{PBH}$, it is found that notch $\mathrm{PBH}$ not only plays a guiding role for explosive energy, which directs more explosive energy to the $\mathrm{TBH}$, and makes the tangential tensile stress of $\mathrm{TBH}$ hole wall greater but also retains concentrate stress for longer time in the hole wall of $\mathrm{TBH}$.

(3) When all the blast hole delay time are $1 \mathrm{~ms}$, if $\mathrm{PBH}$ is a round hole, through cracks can be formed along blast hole attachment direction under blast hole spacing $H_{\mathrm{R}} \leq 17.5 \mathrm{~d}$; if $\mathrm{PBH}$ is a notch hole, through cracks can be formed along blast hole attachment direction under blast hole spacing $H_{\mathrm{R}} \leq 25 \mathrm{~d}$.

The damage depths of the surrounding rock under different $\mathrm{PBH}$ shapes are around $10 \mathrm{~cm}$, and the damage region is smaller when the $\mathrm{PBH}$ is a notch hole. Cracks formation effect is better when the $\mathrm{PBH}$ is a notch hole, but the blast hole notch process is complicated. Therefore, it is necessary to select the appropriate method for rock excavation according to engineering requirements and actual conditions.

\section{Data Availability}

The data used to support the findings of this study are available from the corresponding author upon request.

\section{Conflicts of Interest}

The authors declare that they have no conflicts of interest.

\section{Acknowledgments}

This work was supported by the Fundamental Research Funds for the Chinese Central Universities, China (Grant no. 2016-YB-024) and National Natural Science Foundation of China (nos. 51774222, 51779197, and 51609183), and Doctoral Fund Project BK201816 (170331).

\section{Supplementary Materials}

These supplementary material figures list each figure in the paper in a separate file, the file number corresponds to the number of the figure in the article, including the CAD original figure and the word version screenshot, so that readers can edit it easily. (Supplementary Materials)

\section{References}

[1] M. Cai, P. K. Kaiser, and C. D. Martin, "Quantification of rock mass damage in underground excavations from microseismic event monitoring," International Journal of Rock Mechanics and Mining Sciences, vol. 38, no. 8, pp. 1135-1145, 2001.
[2] M. Cai, P. K. Kaiser, Y. Tasaka, T. Maejima, H. Morioka, and M. Minami, "Generalized crack initiation and crack damage stress thresholds of brittle rock masses near underground excavations," International Journal of Rock Mechanics and Mining Sciences, vol. 41, no. 5, pp. 833-847, 2004.

[3] G. W. Ma and X. M. An, "Numerical simulation of blastinginduced rock fractures," International Journal of Rock Mechanics and Mining Sciences, vol. 45, no. 6, pp. 966-975, 2008.

[4] Z. Zhu, B. Mohanty, and H. Xie, "Numerical investigation of blasting-induced crack initiation and propagation in rocks," International Journal of Rock Mechanics and Mining Sciences, vol. 44, no. 3, pp. 412-424, 2007.

[5] Y. Luo, L. Xin-ping, P.-c. Xu et al., "Characteristic study of surrounding rock mass deformation considering accumulative damage effect," Rock and Soil Mechanics, vol. 35, no. 11, pp. 3041-3048, 2014.

[6] HP. Rossmanith and N. Kouzniak, "Supersonic detonation in rock mass-part 2; particle displacements and velocity fields for single and multiple non-delayed and delayed detonating blastholes," Fragblast, vol. 8, no. 2, pp. 95-117, 2010.

[7] D. P. Blair, "Limitations of electronic delays for the control of blast vibration and fragmentation," in Fragblast 9. Proceedings of the 9th International Symposiumon Rock Fragmentation by Blasting, A. Sanchidria'n, Ed., pp. 171-184, CRC Press, Boca Raton, FL, USA, 2009.

[8] M. Khandelwal and T. N. Singh, "Prediction of blast-induced ground vibration using artificial neural network," International Journal of Rock Mechanics and Mining Sciences, vol. 46, no. 7, pp. 1214-1222, 2009.

[9] S. H. Cho and K. Kaneko, "Rock fragmentation control in blasting," Materials Transactions, vol. 45, no. 5, pp. 17221730, 2004.

[10] U. Longerfors and B. Kihstrom, The Modem Technique of Rock Blasting, John Wiley \& Sons, Hoboken, NJ, USA, 1963.

[11] S. S. Rethore and S. Bhandari, "Controlled fracture growth by blasting while protecting damages to remaining rock," Rock Mechanics and Rock Engineering, vol. 40, no. 3, pp. 317-326, 2007.

[12] W. L. Fourney, D. B. Barker, and D. C. Holloway, "Model studies of well stimulation using propellant charges," International Journal of Rock Mechanics and Mining Sciences \& Geomechanics Abstracts, vol. 20, no. 2, pp. 91-101, 1983.

[13] M. Liang, X. Li, and F. Lu, "Effects of U-notches on the dynamic fracture and fragmentation of explosively driven cylinders," Theoretical and Applied Fracture Mechanics, vol. 77, pp. 50-58, 2015.

[14] G. Yang, Introduction to Elasticity and Plasticity, Tsinghua University Press, Beijing, China, 2004.

[15] D. P. Blair, "A comparison of Heelan and exact solutions for seismic radiation from a short cylindrical charge," Geophysics, vol. 72, no. 2, pp. 33-41, 2007.

[16] J. C. Jaeger, N. G. W. Cook, and R. W. Zimmerman, Fundamentals of Rock Mechanics, Wiley-Blackwell, Oxford, UK, 2007.

[17] China's Hydropower Consulting Group East China Survey Design and Research Institute, The Construction Bidding Documents with Civil Engineering and Metal Structure Installation Project on the Right Bank Diversion Generating System of Jinsha River Baihetan Hydropower Station, China's Hydropower Consulting Group East China Survey Design and Research Institute, Hangzhou, China, 2013.

[18] Q. Li, P. H. Wang, R. S. Yang et al., "Experimental investigation on dynamic mechanical behaviors of cracks 
induced by $\mathrm{V}$-notch blast hole blasting with dynamic caustics," Explosion and Shock Waves, vol. 29, no. 4, pp. 413-418, 2009.

[19] E. L. Lee, H. C. Hornig, and J. W. Kury, "The charge transport problems," Tech. Rep. UCRL-50442, Lawrence Livermore Laboratory, Livermore, CA, USA, 1986.

[20] D. S. Preece and B. J. Thorne, "A study of detonation timing and fragmentation using 3-D finite element techniques and a damage constitutive model," in Rock Fragmentation by Blasting, B. Mohanty, Ed., pp. 147-156, Balkema, Rotterdam, Netherlands, 1996.

[21] L. J. Pyrak-Nolte, Seismic Visibility of Fractures, University of California, Berkeley, CA, USA, 1988.

[22] G. B. Yan and Y. L. Yu, "Numerical simulation of air and water medium decoupling charge blasting," Engineering Blasting, vol. 15, no. 4, pp. 13-19, 2009.

[23] J. Huang, X. Li, Y. Luo et al., "Numerical simulation of influence of filled joint on the crack formed by notch hole blast," European Journal of Environmental and Civil Engineering, pp. 1-17, 2017.

[24] X. P. Li, J. H. Huang, Y. Luo, and P. P. Chen, "A study of smooth wall blasting fracture mechanisms using the Timing Sequence Control Method," International Journal of Rock Mechanics and Mining Sciences, vol. 92, pp. 1-8, 2017.

[25] X. Chen, J. Huang, Y. Luo et al., "Numerical simulation of blast vibration and crack forming effect of rock-anchored beam excavation in deep underground caverns," Shock and Vibration, vol. 2017, Article ID 1812080, 13 pages, 2017.

[26] J. Petzpold and F. Hammelman, "The second generation of electronic blasting systems," in Proceedings of the 1st World Conference on Explosives and Blasting Technique, pp. 159-164, Balkema, Munich, Germany, September 2000. 


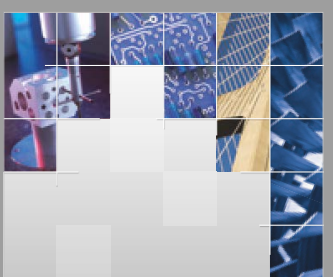

\section{Enfincering}
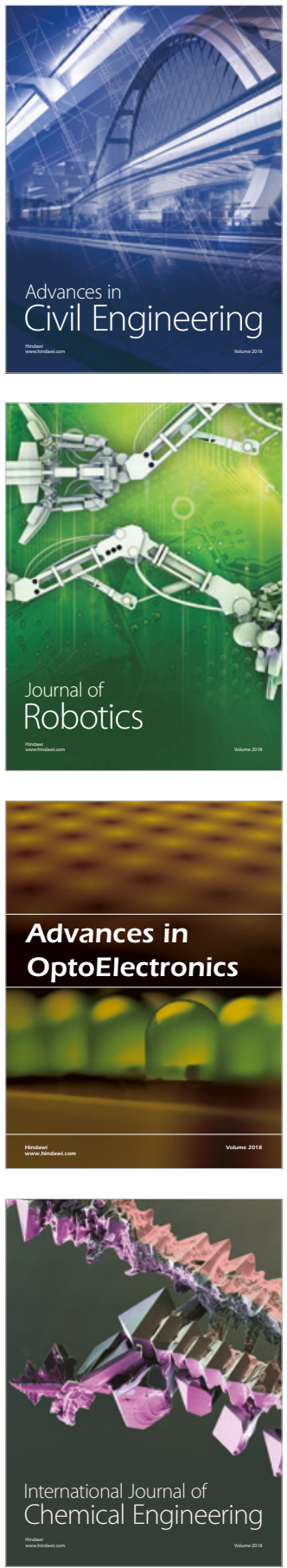

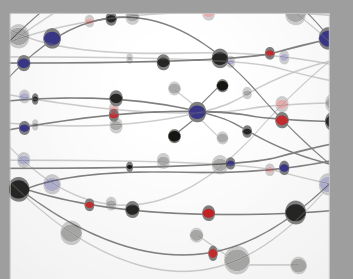

\section{Rotating \\ Machinery}

The Scientific World Journal

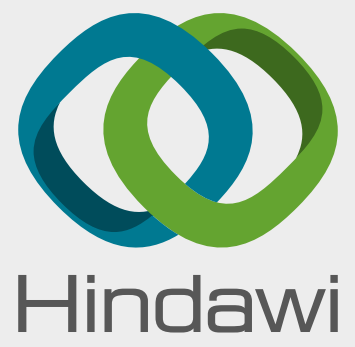

Submit your manuscripts at

www.hindawi.com
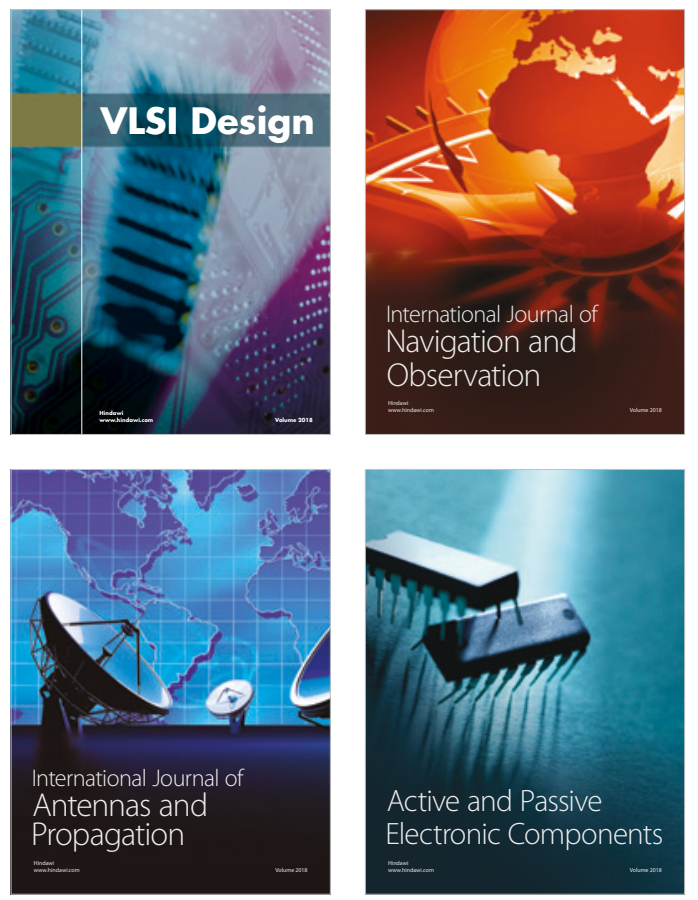
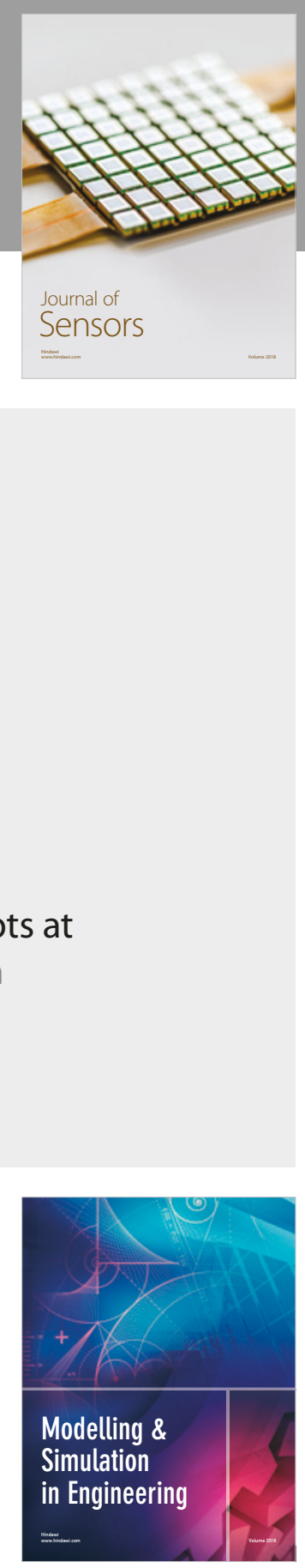

\section{Advances \\ Multimedia}
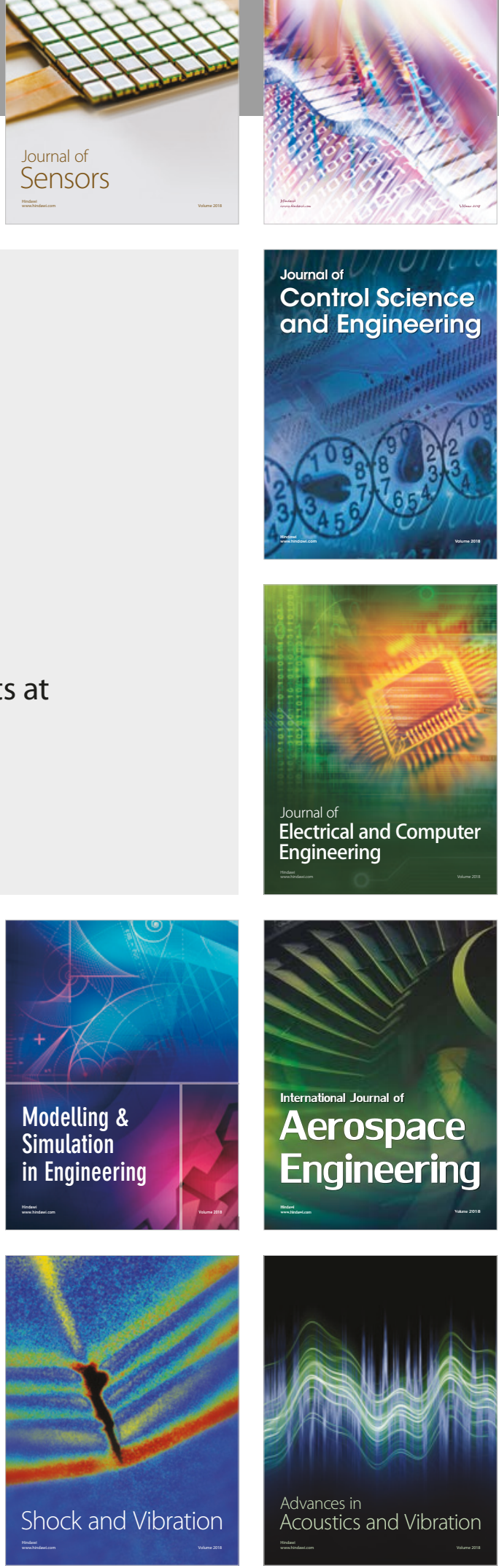